\title{
Watertable fluctuation-induced variability in the water retention curve: Sand column experiments
}

Zhaoyang Luo ${ }^{1,4}$, Jun Kong ${ }^{1,2, \#}$, Zhiling Ji ${ }^{1}$, Chengji Shen ${ }^{1}$, Chunhui Lu ${ }^{1}$, Pei Xin ${ }^{1}$, Zhongwei Zhao $^{1}$, Ling Li $^{3}$, D. A. Barry ${ }^{4}$

${ }^{1}$ State Key Laboratory of Hydrology-Water Resources and Hydraulic Engineering, Hohai University, Nanjing, China

${ }^{2}$ Jiangsu Key Laboratory of Coast Ocean Resources Development and Environment Security, Hohai University, Nanjing, China

${ }^{3}$ School of Engineering, Westlake University, Hangzhou, China

${ }^{4}$ Ecological Engineering Laboratory (ECOL), Environmental Engineering Institute (IIE),

Faculty of Architecture, Civil and Environmental Engineering (ENAC), École Polytechnique Fédérale de Lausanne (EPFL), Lausanne, Switzerland

${ }^{\#}$ Corresponding author: Jun Kong (kongjun999@,126.com)

Journal of Hydrology 589, 2020, 125125

https://doi.org/10.1016/j.jhydrol.2020.125125 


\section{Abstract}

The soil water retention curve (WRC), describing the relation between the soil water content and its corresponding capillary pressure, relies not only on whether drying or wetting occurs but also on the pore scale water flow velocity. Here, we investigated the effects of the watertable fluctuations on the WRC through 28 laboratory experiments covering a wide range of fluctuation amplitudes and periods. Results show that both the response of the capillary pressure and soil water content lag behind the watertable fluctuation, and the vertical capillary pressure distribution in the unsaturated zone is non-hydrostatic, especially for the fluctuations with shorter period. As a consequence of watertable fluctuation, the measured WRC deviates from that under static conditions, depending on both the fluctuation amplitude and period. Moreover, the air-entry pressure under dynamic conditions is considerably larger than that under static conditions, and it first increases and then decreases as the fluctuation period decreases. The effects of the watertable fluctuations on the dynamic capillary coefficient was further examined. It is found that the relation between the dynamic capillary coefficient and saturation is nonunique even for the drying and wetting of a given sand and watertable fluctuation, suggesting a hysteretic dynamic capillary coefficient, and the dynamic capillary coefficient is rate-dependent, decreasing with an increase of fluctuation rate.

Keywords: Water retention curve; watertable fluctuation; sand column experiment; dynamic capillary coefficient 


\section{Highlights:}

The distribution of vertical capillary pressure is non-hydrostatic

$>$ The air-entry pressure values vary with watertable fluctuation period

$>$ The relation between the dynamic capillary coefficient and saturation is nonunique 


\section{Introduction}

Driven mainly by dynamic surface water level, watertable fluctuations usually occur in the aquifers near the rivers, lakes and coastal seas (e.g., Xin et al., 2018). Within inland areas, river water levels are affected by many factors, including episodic rainfall events, evapotranspiration and anthropogenic activities such as regulation of dams (e.g., Larsen et al., 2014; Nilsson et al., 2005; Shuai et al., 2017). Under transient river water level fluctuations, water flows into aquifers during rising river stages and drains out of the aquifers in falling river stages, thus leading to watertable fluctuations. In the coastal areas, watertable fluctuations are more intensive due to low-frequency tides $(12 \mathrm{~h}$ and $12.42 \mathrm{~h}$ for the semidiurnal solar tide and semi-diurnal lunar tide) (Kong et al., 2013; 2015; Li et al., 1997b; 2000b; Shen et al., 2018) and high-frequency random waves (several seconds period) (Hoitink \& Jay, 2016; Li et al., 1997a; Robinson et al., 2018; Xin et al., 2010; 2014).

In general, Richards' or Boussinesq equation is adopted to predict the watertable fluctuation induced by tides and waves in unconfined coastal aquifers (e.g., Barry et al., 1996; Li et al., 1997a; Kong et al., 2013; 2015; Shoushtari et al., 2016). Recent experimental data covering a much wider range of aquifer conditions indicated that the amplitude decay rate and rate of increase in phase lag of the watertable waves monotonically increase as $n \omega D / K_{s}$ increases (where $n$ is the porosity, $\omega$ is the angular frequency, $D$ is the aquifer depth and $K_{s}$ is the saturated hydraulic conductivity) (Shoushtari et al., 2016). However, the existing Boussinesq equations, as well as models based on Richards' equation whether with considering hysteresis or not, cannot explain the experimental results observed by Shoushtari 
et al. (2016). This discrepancy between experimental results and predictions may be due to neglecting watertable fluctuation-induced variability in the soil water retention curve (WRC) that is undetermined.

The WRC, describing the relation between the soil water content $(\theta)$ and its corresponding capillary pressure $\left(P_{c}\right)$, is arguably one of the most important properties of unsaturated soil. Accurate knowledge of the WRC is essential for quantifying unsaturated flow in a variety of hydrological systems and processes, in particular, groundwater recharge, surface runoff, evaporation and solute transport. Also, it can be used to estimate the soil hydraulic conductivity function with capillary bundle models such as that proposed by Burdine (1953) or Mualem (1976). Over the past few decades, great efforts have been made to measure, model and estimate the WRC (e.g., Chin et al., 2010; Cornelis et al., 2001; Crescimanno \& Iovino, 1995; Durner et al., 2011; Kool et al., 1985; Peters, 2013).

Pressure plate tests are commonly applied to determine the WRC where the soil water content and its corresponding capillary pressure are measured after water flow has completely ceased and equilibrium has been established, and hence the obtained WRC is a static relationship (Bittelli \& Flury, 2009; Solone et al., 2012). Measurements of the WRC based on this method are time-consuming and often take weeks or even months to reach the equilibrium at each capillary pressure, especially for fine porous media. Moreover, the whole measurement process yields only a limited number of water retention data points. Therefore, other methods for rapid measurement of the WRC have been proposed. For more details regarding this topic, the readers may refer to the comprehensive review of Haghverdi et al. 
(2018).

The measured WRC relies not only on whether imbibition or drainage takes place but also on pore scale water flow velocity. Topp et al. (1967) first conducted drainage experiments to compare the WRC under different flow conditions, including both static and dynamic states. They found that soil water content measured under dynamic (transient) conditions was significantly higher than that measured under static conditions at a given capillary pressure, and consequently that the WRC was related to the flow conditions. These findings were supported by experiments of Stauffer (1978) and Schultze et al. (1997). Subsequently, O'Carroll et al. (2005) explored dynamic effects on capillary pressure with multistep outflow experiments. They indicated that a non-equilibrium instead of a static WRC should be adopted when modeling multistep drainage processes.

In addition to laboratory experiments, numerical models have also been used to investigate dynamic effects on the WRC (Diamantopoulos et al., 2012; 2015; Joekar-Niasar et al., 2010). Stauffer (1978) and Hassanizadeh and Gray (1990) proposed an approach to quantify dynamic effects on the WRC where the dynamic capillary pressure component depends on the time derivative of saturation through a capillary dynamic coefficient $\tau$ $\left(\mathrm{ML}^{-1} \mathrm{~T}^{-1}\right)$. We refer to the comprehensive review of Hassanizadeh et al. (2002) for more information about $\tau$. This approach has been widely adopted with subsequent studies focusing on the value of $\tau$ (Diamantopoulos and Durner, 2012). Both numerical and experimental studies show that the value of $\tau$ could vary over a wide range (Bottero et al., 2011; Camps-Roach et al., 2010; Hassanizadeh et al., 2002). The value of $\tau$ is influenced by 
a variety of factors, including saturation, spatial scale and fluid viscosity (Abidoye \& Das, 2014). Recently, Lo et al. (2017) examined the response of the WRC to acoustic excitations during drainage and found that $\tau$ values were smaller than those without adding such excitations. They attributed this decrease to the combination of the increase in the permeability and the decline in the air-entry pressure due to the acoustic excitations. Given that almost all studies mentioned involved primary drainage processes, Zhuang et al. (2017) reported experiments to estimate $\tau$ during scanning drainage processes. They indicated a dependence of $\tau$ on saturation for all drainage conditions and found that the values of $\tau$ for primary drainage were larger than those for the main and scanning drainage curves. More recently, Li et al. (2019) investigated factors influencing $\tau$ with both smooth and stepwise drainage experiments. Their results suggested that the value of $\tau$ was more correlated with the water saturation and its temporal rate of change.

Watertable fluctuations widely exist in nature and hence it is critical to investigate the effects of watertable fluctuations on the WRC. However, compared with studies on either wetting or drainage processes (or both), the effects of watertable fluctuations on the WRC have received limited attention in the literature (Cartwright, 2014). Moreover, no experimental studies have been conducted to provide any information on $\tau$ under different watertable fluctuations. As the WRC plays a critical role in modeling unsaturated flow, the investigation of the watertable fluctuation-induced variability in the WRC would enhance the predictions of the dynamic watertable which forms a basis for improving the understanding of the groundwater-dependent ecological and biogeochemical processes. 
In this study, we performed a series of laboratory experiments in a sand column where different watertable fluctuations covering a wide range of amplitudes and periods were imposed at the bottom boundary. This allowed us to measure the WRC under different watertable fluctuations and to further quantify the effects of the watertable fluctuations on the WRC. We focus primarily on high-frequency water table fluctuations (period $<6$ hours), such as those induced by random waves. Our objectives were (1) to examine the vertical capillary pressure distribution in the unsaturated zone during watertable fluctuations; (2) to reveal watertable fluctuation-induced variability in the water retention curve, and (3) to obtain values of the dynamic capillary coefficient $(\tau)$ under different watertable fluctuations.

\section{Materials and Methods}

\subsection{Sand}

The well-sorted and relatively uniform medium sand used in the experiments was obtained from a sand producer in Nanjing, China. Prior to filling the column, the sand was thoroughly washed with deionized water to remove fine particles. The sand's particle size distribution was measured by a laser diffraction particle size analyzer (Malvern Panalytical, Mastersizer 3000, accuracy of $\pm 0.6 \%$ ), with $d_{50}=0.803 \mathrm{~mm}$ (median grain size) and $d_{90} / d_{10}=1.82$ (Figure 1). The sand has a saturated hydraulic conductivity of $4.57 \times 10^{-3} \mathrm{~m} / \mathrm{s}$ (Darcy column test) and an effective porosity of 0.39 (oven-drying method). The dry bulk density was $1.52 \mathrm{~g} / \mathrm{cm}^{3}$. Also, we measured the soil volumetric water content (weighing method) and capillary pressure (HITACHI CR21GII high speed refrigerated centrifuge), which were applied to obtain the van Genuchten (VG) parameters (van Genuchten, 1980) for 
the main drying curve (cf. section 2.4). We refer to Reatto et al. (2008) for more details regarding the centrifuge method to determine the WRC. The same sand has been used in laboratory experiments investigating different phenomena, including hillslope recession characteristics (Luo et al., 2018), groundwater and surface water interaction (Xin et al., 2018) and seawater intrusion in unconfined coastal aquifers (Yu et al., 2019). Using the measured static main drying curve in numerical models, all three studies obtained predictions that agree well with laboratory measurements. Therefore, this static main drying curve can be considered to be reasonable. Following Kool and Parker (1987), the VG parameters for the main wetting curve were scaled from those of the main drying curve with the scale parameter equal to 2. For the scaling method, readers can refer to the Table 1. Below, the subscripts "d" and "w" refer to the drying and wetting curves, respectively (sand hydraulic properties are summarized in Table 1). It should be noted that such scaling methods have been shown to be acceptable as first-order approximations, but experimental evidence to support them for a wide range of soil types and test conditions remains limited (Likos et al., 2014).

\subsection{Experimental Setup}

Figure 2 depicts the experimental setup for investigating the watertable fluctuationinduced variability in the WRC. The apparatus consists of a sand column and a fluctuation generator, both constructed from the clear acrylic tube. To reduce the response time of the watertable in the sand column, five hoses with an inner diameter of $0.025 \mathrm{~m}$ were used the generator and the column. The sand column was $1.8 \mathrm{~m}$ in height with an inner diameter of $0.18 \mathrm{~m}$. The column was impermeable. Its top boundary was open to the atmosphere, and its 
bottom boundary was composed of a porous plate and highly permeable geofabric that separated the sand from a clear water cell linked to the fluctuation generator. A stepper motor with 20,000 steps per revolution (Nimotion Inc.) was connected using a steel cable $(0.002 \mathrm{~m}$ diameter) to the cylinder sleeve in the fluctuation generator, which changed the watertable. Readers are referred to Jin et al. (2014) for details on how to generate the sinusoidal signal. With this system, a wide range of watertable fluctuations could be generated with amplitudes varying from 0 to $0.25 \mathrm{~m}$ and periods varying from 60 to $20000 \mathrm{~s}$.

The soil water content and capillary pressure at different depths are nonuniform because of the non-negligible height of the sand column (Cartwright, 2014; Lo et al., 2017). Three Time Domain Reflectometry (TDR) probes (Acclima, TDR-315L, accuracy of $\pm 2 \%$ ) were installed at $z=0.17,0.27$ and $0.42 \mathrm{~m}$ (relative to mean driving head level set at $0.72 \mathrm{~m}$ below the sand surface) to measure the soil water content at different locations. Three UMS T5 tensiometers (METER, $0.04 \mathrm{~m}$ length shaft, accuracy of $\pm 0.5 \mathrm{kPa}$ ) were used to measure the vertical distribution of capillary pressure. Two of these tensiometers were co-located with the second and third TDR probes (i.e., $z=0.17$ and $0.27 \mathrm{~m}$ below the sand surface) while the third was placed at $z=0.23 \mathrm{~m}$. To avoid interactions between the tensiometers and TDR probes, the tensiometers were installed perpendicularly to the TDR probes (supporting information Figure $\mathrm{S} 1)$. The response time of the TDR probes was $0.7 \mathrm{~s}$, whereas that for the tensiometers was a few milliseconds. These fast response times ensure the reliability of the transient soil water content and capillary pressure variations induced by watertable fluctuations. The watertable fluctuation imposed at the sand column base was measured through a high-resolution 
piezometer (WIKA, S10, accuracy of $2.5 \mathrm{~mm}$ ), installed at a depth of $1.3 \mathrm{~m}$ below the sand surface. The TDR probes, tensiometers and the piezometer were connected to a Campbell Scientific CR3000 data logger, where all of the measured data were recorded and stored at 10s intervals. For more details about the experimental apparatus, readers are to referred to Luo et al. (2019a).

To avoid air encapsulation or layering effects on the measurements, the column was filled carefully following previous studies (Li et al., 2019; Sakaki et al., 2010). First, the column was gradually filled with deionized water. The washed sand was then poured into the column (through a funnel) from the top while maintaining the water level higher than the sand surface. After adding approximately $0.1 \mathrm{~m}$ of sand, it was compacted by tapping the column with a rubber mallet. These steps were repeated until the desired sand height in the column was reached. To allow further subsidence of the sand under gravity, the column was maintained statically for $15 \mathrm{~d}$ after filling. During this time, the sand subsided slightly, so a small amount of sand was added to make the sand surface horizontal with the top of column.

\subsection{Experimental Procedures}

All the experiments were conducted in April 2019, during which the room temperature was about $20^{\circ} \mathrm{C}$. Prior to installing the experimental column, the TDR probes, T5 tensiometers and S10 piezometer were individually calibrated to ensure the accuracy of measurements. For calibration, the soil water contents measured from the TDR probes were compared with those obtained from the weighing method, whereas the T5 tensiometers and S10 piezometer were used to measure hydrostatic pressures at different heights. 
The experiments were carried out $15 \mathrm{~d}$ after filling the column. Three different watertable fluctuation amplitudes $(A)$ were imposed: $0.09,0.14$ and $0.19 \mathrm{~m}$. Accordingly, we considered ten fluctuation periods (T) (i.e., 20000, 10000, 5000, 4000, 2857, 1818, 1250, 909, 588 and 299 s) for each amplitude. Note that these fluctuation periods correspond primarily to high-frequency random waves and some regulated rivers. Since the damping rate of the fluctuation amplitude increases with decreasing period (Kong et al., 2013; 2015), the experimental apparatus cannot produce fluctuations with periods of 588 and $299 \mathrm{~s}$ for an amplitude of $0.19 \mathrm{~m}$. Therefore, a total of 28 , instead of 30 experiments was performed. For all experiments, the mean driving head level of fluctuations was fixed at the same depth of $0.72 \mathrm{~m}$ below the sand surface, where the $z$ coordinate origin is placed with the $z$-axis pointing vertically upward. Using a similar sand column, Cartwright et al. (2004) indicated that the effects of truncation of unsaturated zone become insignificant for $z_{s} \geq A+0.5 H_{\psi}$, in which $z_{s}[\mathrm{~L}]$ is sand surface elevation, $A[\mathrm{~L}]$ is fluctuation amplitude and $H_{\psi} \quad[\mathrm{L}]$ is the capillary fringe height. In this study, $z_{s}$ was $0.72 \mathrm{~m}$, the maximum $A$ was $0.19 \mathrm{~m}$ and $H_{\psi}$ was about $0.10 \mathrm{~m}$. Therefore, the effects of truncation of the unsaturated zone on the experimental data can be ignored.

At the beginning of each experiment, the stepper motor was run to create the fluctuations imposed on the sand column base, which were monitored using the S10 piezometer. The generated fluctuation was considered to be acceptable when the total deviation of the amplitude and mean driving head was smaller than $0.005 \mathrm{~m}$. Two replicates were conducted for each set of experiments starting from the lowest watertable height. Concurrently, 
porewater pressures, soil water contents and capillary pressures were recorded.

\subsection{Describing the WRC}

The van Genuchten (1980) formula (referred to as the VG model) was employed to describe the WRC,

$$
P_{c}=\frac{1}{\alpha}\left(S_{w}^{-1 / m}-1\right)^{1 / n}
$$

where $P_{c}\left[\mathrm{ML}^{-1} \mathrm{~T}^{-2}\right]$ is the capillary pressure, $S_{w}[-]$ is the effective saturation, $\alpha\left[\mathrm{L}^{-1}\right], n$ $[-]$ and $m[-]$ are fitting parameters related to the soil properties with $m=1-1 / n$.

Following Luo et al. (2019b), a nonlinear regression algorithm, namely the Matlab

$\left(\mathrm{MATLAB}^{\circledR}\right.$ ver. 9) function "lsqcurvefit" (solves nonlinear curve-fitting problems using the least-squares criterion), was used to determine these parameters via fitting the VG model to the experimental data. The effective saturation $S_{w}$ is defined as,

$$
S_{w}=\frac{\theta-\theta_{r}}{\theta_{s}-\theta_{r}}
$$

where $\theta[-]$ is the soil water content, $\theta_{s}[-]$ and $\theta_{r}[-]$ represent the saturated and residual soil water contents, respectively.

\subsection{Calculation of the Dynamic Capillary Coefficient}

In the present study, we followed Hassanizadeh and Gray (1990) to account for the dynamic effects on the WRC due to watertable fluctuations. Hence, the dynamic capillary pressure is related to the flow dynamics through the time derivative of saturation,

$$
P_{n}-P_{w}-P_{c}=-\tau \frac{\partial S_{w}}{\partial t}
$$

where $P_{n}$ and $P_{w}$ are nonwetting-phase and wetting phase pressures under dynamic

conditions, respectively, $P_{c}$ is the capillary pressure under static conditions, $S_{w}[-]$ is as 
described in equation (2). Following previous studies (Hassanizadeh et al., 2002; Sakaki et al., 2010), $P_{n}-P_{w}$ and $P_{c}$ are respectively referred to as the dynamic capillary pressure $P_{c}^{d y n}$ and static capillary pressure $P_{c}^{\text {sta }}$ for the sake of convenience and hence equation (3) can be written as,

$$
P_{c}^{d y n}-P_{c}^{s t a}=-\tau \frac{\partial S_{w}}{\partial t}
$$

Generally, $\tau$ in equation (4) is not a constant and depends on material properties and the state of the system (O'Carroll et al., 2005). Previous work indicated that an increase in the time needed to achieve equilibrium would increase $\tau$ (Juanes, 2008).

The values of $\tau$ during the watertable fluctuations were calculated following Li et al. (2019), who approximated the time derivative in equation (4) with a constant step, $\Delta t$,

$$
\tau_{i}=-\frac{\left(P_{c}^{d y n(i)}-P_{c}^{s t a(i)}\right)\left(t^{i+1}-t^{i}\right)}{S_{w}^{i+1}-S_{w}^{i}}
$$

where $i$ and $i+1$ denote $P_{c}^{d y n}, P_{c}^{s t a}$ and $S_{w}$ at times $t$ and $t+\Delta t$, respectively.

Because of the resolution of the TDR probes, the value of $\tau$ estimated from equation (5) is only reliable when the change between two consecutive saturation readings is greater than $0.5 \%$, otherwise $\tau$ is calculated from,

$$
\tau_{q}=-\frac{\left(\frac{1}{k+1} \sum_{i=u}^{u+k} P_{c}^{d y n(i)}-\frac{1}{k+1} \sum_{i=u}^{u+k} P_{c}^{s t a(i)}\right)\left(t^{u+k}-t^{u}\right)}{S_{w}^{u+k}-S_{w}^{u}}
$$

where $u$ and $u+k$ indicate $P_{c}^{d y n}, P_{c}^{\text {sta }}$ and $S_{w}$ at the time $t$ and $t+k \Delta t$ respectively, and $q$ is the average of $u$ and $u+k$, equaling $u+\frac{k}{2}$. The integer $k$ is determined according to the following condition:

$$
\left|S_{w}^{u+k}-S_{w}^{u}\right| \geq 0.5 \%
$$


Note that the abovementioned calculation approach used to estimate $\tau$ is similar to the variable time step method widely adopted in hillslope recession flow analysis (Rupp \& Selker, 2006).

For comparison, we also estimated $\tau$ according to Barenblatt's approach where dynamic effects in capillary pressure are related to the redistribution time. Using a first-order approximation, the dynamic capillary coefficient estimated from equation (4) can be related to the redistribution time $\tau_{b}$ (Juanes, 2008),

$$
\tau\left(S_{w}\right)=\frac{d P_{c}^{s t a}}{d S_{w}} \tau_{b}
$$

where $d P_{c}^{\text {sta }} / d S_{w}$ is calculated according to equation (1) and then $\tau_{b}$ is obtained by fitting equation (8) to the $\tau$ calculated from equation (4).

\section{Results and Discussion}

\subsection{Responses of Capillary Pressure and Soil Water Content}

As mentioned earlier, we considered three fluctuation amplitudes with 10 fluctuation periods for two amplitudes $(0.09$ and $0.14 \mathrm{~m})$ and eight fluctuation periods for the other $(0.19$ m). Two experiments, the longest (20000 s) and shortest periods (299 s) with an amplitude of $0.14 \mathrm{~m}$, are selected as representative cases to illustrate the responses of capillary pressure and soil water content to watertable fluctuations. For both experiments, the capillary pressure and soil water content time series of two replicates (two periods) are almost identical (Figures 3 and 4). It should be noted that this is also the case for the other set of experiments with data presenting in the Supporting Information.

Several trends can be found in the capillary pressure and soil water content time series 
for the longer period (Figure 3). First, the responses of the capillary pressure and soil water content lag behind the watertable fluctuation and both the capillary pressure and soil water content reach a minimum prior to the low water level. This minimum value remains unchanged until the water level is high enough. Second, the asymmetry regrading high water level (HWL) is observed in plots of capillary pressure and soil water content versus time especially for the higher elevation $(z=0.27 \mathrm{~m})$, suggesting that the duration of wetting is shorter than that of drying. Third, there is a significant decrease in the ranges of both the capillary pressure and soil water content with increasing elevation. At $z=0.17 \mathrm{~m}$ (Figure 3b), the capillary pressure and soil water content respectively vary from -0.03 to $-0.186 \mathrm{~m}$ and 0.026 to 0.372 . Far from the watertable $(z=0.27 \mathrm{~m}$, Figure $3 \mathrm{c})$, the ranges of capillary pressure and soil water content reduce to $-0.133 \sim-0.19 \mathrm{~m}$ and 0.024 to 0.06 , respectively. Note that at $z=0.17 \mathrm{~m}$ (Figure $3 \mathrm{~b}$ ), the soil water content attains its maximum value before the HWL and is unchanged for a period of time at the transition between the rise and fall of the watertable due to the extension of capillary fringe above the watertable (Brakenhoff et al., 2019).

The above three trends appear again with decreasing fluctuation period (Figure 4 for a period of 299 s). By comparison, the lag of capillary pressure and soil water content behind the watertable become more significant for the shorter period. At $z=0.17 \mathrm{~m}$ (Figures $4 \mathrm{~b}$ ), the capillary pressure and soil water content respond mainly when the watertable is falling, whereas the capillary pressure and soil water content even do not respond to the watertable at $z=0.27 \mathrm{~m}$ (Figures $4 \mathrm{c})$. As a consequence, both the range of capillary pressure and soil water 
content are smaller in particular at $z=0.27 \mathrm{~m}$ with nearly constant values. This suggests that the water exchange between the watertable and above unsaturated zone reduces with decreasing the fluctuation period.

With the Dupuit-Forchheimer approximation adopted, the vertical capillary pressure distribution is usually assumed to be hydrostatic for the unsaturated zone (Kong et al., 2013; 2015). However, until now few experiments examined whether this assumption is reasonable for a fluctuating watertable. Figures 5 and 6 show the capillary pressure time series at three different locations for two experiments with the same fluctuation amplitude $(0.14 \mathrm{~m})$ but different periods, 20000 and 299 s. For the fluctuation period of $20000 \mathrm{~s}$, the maximum capillary pressure decreases with increasing elevation, while the minimum capillary pressure is almost the same, close to $-0.2 \mathrm{~m}$, regardless of the elevation (Figure 5a). Six characteristic states between two high water levels were chosen to illustrate the vertical capillary pressure distribution (Figures 5b-g). As can be seen, at 9200, 11600 and $26900 \mathrm{~s}$, the capillary pressure distribution is nearly hydrostatic from $z=0 \mathrm{~m}$ to $z=0.27 \mathrm{~m}$. Further, at $14100 \mathrm{~s}$, the pressure profile is hydrostatic from 0 to $0.23 \mathrm{~m}$. In contrast, the distribution is non-hydrostatic between 19200 and $24200 \mathrm{~s}$ (capillary pressures are almost the same at the three locations) when the watertable is low. This indicates that there is a location above which the capillary pressures keep the same minimum value and hence the assumption of hydrostatic capillary pressure distribution is only reasonable for areas from the watertable to this location. The reason why the capillary pressures keep the same minimum above a location is the hydraulic discontinuity (discontinuous capillary pathways) in the upper unsaturated zone far away from the water 
table, where air phase instead of liquid phase dominates (Or et al., 2015).

Compared with the period of $20000 \mathrm{~s}$, the maximum capillary pressure becomes smaller while the minimum capillary pressure is still the same for the period of $299 \mathrm{~s}$ (Figure 6a). At $z$ $=0.17 \mathrm{~m}$, the capillary pressure varies in a small range from -0.15 to $-0.07 \mathrm{~m}$ and the maximum value lags behind the HWL. Far from the watertable $(z=0.23$ and $0.27 \mathrm{~m})$, the capillary pressures remain unchanged during the watertable fluctuation. This is because the watertable fluctuate rate is higher than the pore water redistribution rate and hence the capillary pressure does not have sufficient time to respond to the groundwater fluctuation. Consequently, the capillary pressure distribution is always non-hydrostatic for the period of $299 \mathrm{~s}$ (Figures 6b-g). Note that the capillary pressure at $z=0 \mathrm{~m}$ is assumed to be the watertable level for both experiments.

\subsection{Effects of Watertable Fluctuation on the WRC}

Figure 7 shows the measurements of the WRC for different watertable fluctuations that have the same amplitude of $0.09 \mathrm{~m}$ but cover a range of periods. Note that the results of two replicates are almost the same and hence the last replicate is presented for the sake of conciseness. As mentioned before, the soil water content and capillary pressure at different depths are nonuniform because of the non-negligible height of sand column. At the location of $z=0.27 \mathrm{~m}$, the extent of the dynamic hysteretic loop is small and nearly unchanged due to the distance from the watertable and minor capillary effects of the sand used in experiments. In contrast, for the location where $z=0.17 \mathrm{~m}$ (i.e., closer to the watertable), the dynamic hysteretic loop indicates a strong dependence on the fluctuation period, consistent with the 
findings of Cartwright (2014). For fluctuations with longer periods, a clear hysteretic loop can be observed between the dynamic drying and wetting curves. As the fluctuation period decreases, the extent of the hysteretic loop significantly reduces and almost disappears for fluctuation periods less than $1250 \mathrm{~s}$. In other words, the dynamic drying and wetting curves are closer, even coincide with each other as the fluctuation period decreases. For example, for the shortest period of $299 \mathrm{~s}$, the dynamic hysteretic loop is compressed with a small variation. This is because the unsaturated zone has insufficient time to respond to watertable fluctuations with shorter periods and an equilibrium between the soil water content and capillary pressure cannot be established even at locations closer to the watertable. Moreover, although the dynamic hysteretic loop is inside the static hysteretic loop, both the dynamic drying and wetting curves at $z=0.17 \mathrm{~m}$ deviate from those measured under static conditions, in particular the drying curves.

To further investigate the effects of the watertable fluctuations on the WRC, we conducted additional experiments with varying the fluctuation amplitudes. Results for the fluctuation amplitudes of 0.14 and $0.19 \mathrm{~m}$ are respectively shown in Figures 8 and 9. Again, the extent of the dynamic hysteretic loop is closely related to the fluctuation period, even at $z$ $=0.27 \mathrm{~m}$ far from the watertable. Also, the dynamic WRC differs from the static WRC especially for the drying curve although the dynamic hysteretic loop is inside the static hysteretic loop at both locations. By comparison, for a constant fluctuation period, the extent of the dynamic hysteretic loop greatly increases with increasing fluctuation amplitude (Figures 7-9). This highlights that the WRC is affected by both the fluctuation period and the 
fluctuation amplitude. Note that, for the sake of conciseness, the measured WRC curves for watertable fluctuations with a period of $4000 \mathrm{~s}$ and amplitudes of 0.09 and $0.14 \mathrm{~m}$ are presented in Figure S2 (supporting information).

\subsection{Values of Fitting Parameters and Air-entry Pressure}

The VG model was respectively fitted to the dynamic drying and wetting curves measured at $z=0.17 \mathrm{~m}$. Here, we focused on the experiments with fluctuation amplitudes of 0.14 and $0.19 \mathrm{~m}$ where the saturated water contents can be obtained (Figures 8 and 9). Note that, due to air entrapment, the saturated water contents measured under watertable fluctuations are slightly smaller than those measured under static conditions. Therefore, the maximum soil water content in each experiment was considered to be saturated soil water content. For the residual soil water content, we set a constant value of 0.01 that is the minimum reading of TDR at $\mathrm{z}=0.17 \mathrm{~m}$ achieved in all experiments focused on this section except for three experiments with amplitude of $0.14 \mathrm{~m}$ and periods of $909 \mathrm{~s}$ (Figure 8g), $558 \mathrm{~s}$ (Figure 8h) and $299 \mathrm{~s}$ (Figure 8i). In these three experiments, the minimum water contents are respectively $0.03,0.04$ and 0.05 due to insufficient time to respond to the watertable fluctuations. Additionally, this residual water content of 0.01 is the same as that measured from the static experiment, as described above.

As can be seen, both the values of $\alpha_{d}$ and $n_{d}$ become larger for the dynamic drying curves; the values of $\alpha_{w}$ decrease while the values of $n_{w}$ increase for the dynamic wetting curves (Figure 10). Compared with the fluctuation amplitude of $0.14 \mathrm{~m}$, the values of $\alpha$ and

$n$ can vary over a wider range for the fluctuation amplitude of $0.19 \mathrm{~m}$. Moreover, whether for 
the dynamic drying or wetting curve, values of $\alpha$ decrease while values of $n$ increase with increasing fluctuation amplitude. Based on the above comparison, we can conclude that the values of $\alpha$ and $n$ for the dynamic WRC would deviate from those of the static WRC, depending on both the fluctuation period and amplitude. Previous studies suggest that $\alpha$ decreases monotonically with increasing $\mathrm{d} S_{w} / \mathrm{d} t$ for drainage processes (Camps-Roach et al., 2010; Li et al., 2019; Sakaki et al., 2010). However, in our experiments, $\alpha$ first decreases and then increases as the fluctuation period decreases for both drying and wetting (Figures 10a,c). The increase of $\alpha$ for shorter fluctuation periods can be explained as follows: As the fluctuation period decreases, the watertable fluctuate rate becomes larger and then the pores have no time to respond to the water flow, resulting an increase in $\alpha$. The trend of air-entry pressure discussed below can further confirm the increase of $\alpha$ for shorter fluctuation periods due to its inversely proportional relation (Guarraticino et al., 2007).

The rate-dependence of air-entry pressure has also been reported in the literature (Abidoye \& Das, 2014; Rabbani et al., 2016). Since the value of $\alpha$ for the dynamic WRC differs greatly from that for the static WRC even for a given soil (Figure 10a,c), it is intuitive to examine the effects of watertable fluctuation on the air-entry pressure. According to Corey (1994), the air-entry pressure is defined as the air pressure required to force air through an initially water-saturated sample. Generally, the air-entry pressure is equal to the displacement pressure, which can be estimated by fitting Brooks and Corey (1964) formula to the pairs of capillary pressure and effective saturation data. Nevertheless, the displacement pressure estimated from above fitting method was slightly larger than the air-entry pressure. Visual 
determination of the inflection point along the WRC is a more accurate method to obtain airentry pressure (Corey, 1994; Li et al., 2019).

The experiments with fluctuation amplitude of $0.19 \mathrm{~m}$ further allow us to examine the effects of watertable fluctuation on the air-entry pressure estimated visually. As can be seen, the air-entry pressure under dynamic conditions is considerably larger than that under static conditions, regardless of wetting and drying (Figure 11). In addition, the air-entry pressure first increases and then decreases as the fluctuation period decreases. These trends can be interpreted as follows: The pore distribution in the porous media is complicated and usually nonuniform. Under steady static conditions, there is sufficient time for water flow to reach to/drain from all the pores regardless of pore size. This is not the case under watertable fluctuations. When the watertable lowers air enters the medium, while some of the air is trapped when the watertable raises, blocking some of the larger pores which would increase the air-entry pressure. This is consistent with findings of Li and Berkowitz (2018), whose results indicated that the final resident water saturation for the fast flux is higher than that for the slow flux, suggesting less available pores and hence higher air-entry pressure for the fast flux. However, when the fluctuation rate continues to increase, pores would have no time to respond to the water flow which causes water to stay behind and hence the air-entry pressure decreases. Note that the trend of air-entry pressure is consistent with $\alpha$ since the air-entry pressure is inversely proportional to $\alpha$. Li et al. (2019) observed an increasing air-entry pressure with increasing flow velocity. This is because the maximum flow rate in their experiments was $2.59 \times 10^{-4} \mathrm{~m} / \mathrm{s}$, two orders of magnitude smaller than the average 
fluctuation rate of $1.9 \times 10^{-2} \mathrm{~m} / \mathrm{s}$ in our experiment with amplitude of $0.19 \mathrm{~m}$ and period of $4000 \mathrm{~s}$. Thus, the pore water blockage may not occur in their experiments.

\subsection{Values of Dynamic Capillary Coefficient}

Noticeably, the measured WRC under the watertable fluctuation shows a significant deviation from that measured under static conditions, depending on both the fluctuation amplitude and period. In previous works, the dynamic capillary coefficient $\tau$ was adopted to characterize dynamic effects on the WRC (Hassanizadeh et al., 2002; Hassanizadeh \& Gray, 1990; Sakaki et al., 2010; O’Carroll et al., 2005). However, the effects of watertable fluctuations on the value of $\tau$ were not reported. Because of small saturation range for the experiments with amplitude of $0.09 \mathrm{~m}$, we calculated the values of $\tau$ at $z=0.17 \mathrm{~m}$ according to equation (4) for watertable fluctuations with amplitudes of 0.14 and $0.19 \mathrm{~m}$. It is worth noting that at a few given $S_{w}$, the measured $P_{c}^{d y n}$ is lowerlhigher than $P_{c}^{\text {sta }}$ during drying $\mid$ wetting, which would induce a negative $\tau$ (Figures 8 and 9). One possible reason why the measured point outside the static loop is that the static main wetting curve is scaled from static main drying curve. In addition, an increasing of air-entry pressure value compared with static conditions would also result in measured points during drying processes outside the static loop (Figure 9). In this paper, the values of $\tau$ at these points were abandoned which would not impact the general trend of $\tau$ due to very few negative points.

Figure 12 shows the calculated $\tau$ values according to equation (4) for the watertable fluctuations with amplitude of $0.14 \mathrm{~m}$ (colored circles). For all six fluctuation periods, the values of $\tau$ vary over a wide range (approximately from $10^{4}$ to $10^{7} \mathrm{~Pa} \mathrm{~s}$ ), which is in line 
with previous estimations from other drainage experiments, i.e., $3 \times 10^{4}$ to $5 \times 10^{7} \mathrm{~Pa} \mathrm{~s}$ (Camps-Roach et al., 2010; Hassanizadeh et al., 2002). Moreover, a strong dependence of $\tau$ on saturation was found for both drying and wetting. The magnitude of $\tau$ generally increases with decreasing saturation. For example, during drying for the case of a fluctuation amplitude of $0.14 \mathrm{~m}$ and a period of $20000 \mathrm{~s}$ (Figure 12a), $\tau$ first reaches its minimum value at a saturation of around 0.85 , and then increases log-linearly with decreasing saturation until a saturation of 0.15 is reached. A similar trend can also be found in wetting. For lower saturations, a drastic increase of $\tau$ occurs. This is due to small time derivative of saturation $\left(\partial S_{w} / \partial t\right)$ while large $P_{c}^{d y n}-P_{c}^{s t a}$ for saturations smaller than 0.15 . Consistent with our experimental results, Zhang et al. (2017) has reported that the value of $\tau$ first decreased then increased nearly log-linearly with decreasing saturation in both primary and main drainage experiments.

The $\tau$ values calculated from equation (4) also indicate that the relationship between the dynamic capillary coefficient $\tau$ and saturation $S_{w}$ is nonunique, even for drying and wetting of a given sand and watertable fluctuation (colored circles in Figure 12). The values of $\tau$ are generally larger for drying than those for wetting at the same saturation, suggesting a hysteretic $\tau$ induced by watertable fluctuation. Likewise, a dependence of $\tau$ on the fluctuation period can be found. The range of $\tau$ decreases with decreasing the fluctuation periods, especially for drying. During drying for the case of a fluctuation amplitude of $0.14 \mathrm{~m}$, $\tau$ mainly varies from $10^{5}$ to $10^{7} \mathrm{~Pa}$ s for the period of $20000 \mathrm{~s}$ (Figure 12a), whereas these values change from $10^{4}$ to $10^{6} \mathrm{~Pa}$ s for the period of $909 \mathrm{~s}$ (Figure $12 \mathrm{f}$ ). A nonunique $\tau-S_{w}$ 
relationship was also reported by Mirzaei and Das (2013) and Sakaki et al. (2010) when investigating the dynamic effects in capillary pressure for the main drainage and imbibition processes. Recently, Zhang et al. (2017) found a different $\tau-S_{w}$ relationship for the primary, main and scanning drainage curves. They attributed the nonunique $\tau-S_{w}$ relationships to different pore water redistributions which are not available in their experiments. Our results show that the hysteresis in the WRC could be another factor to induce this nonunique $\tau-S_{w}$ relationship during watertable fluctuations. Further studies are necessary to reveal the pore water redistribution process during watertable fluctuations and its relationship with dynamic capillary pressure.

To further investigate the effects of watertable fluctuations on $\tau$, we calculated $\tau$ values from equation (4) for the watertable fluctuations with amplitude of $0.19 \mathrm{~m}$. Results are depicted in Figure 13 with colored circles. Again, a hysteretic $\tau$ was found, i.e., a different value for drying and for wetting at the same saturation, while the range of $\tau$ decreases with a decreasing of fluctuation period. Note that $\tau$ values for wetting become larger than those for drying at higher saturations. This is because the increase of the air-entry pressure compared with that of static conditions (Figure 9). By comparison, when the fluctuation amplitude increases from 0.14 to $0.19 \mathrm{~m}, \tau$ decreases for the same fluctuation periods, in particular for drying. These results again confirm a dependence of $\tau$ on flow rate. When the fluctuation amplitude is $0.14 \mathrm{~m}$, the average flow velocities for the fluctuation periods of 20000 and $909 \mathrm{~s}$ are, respectively, $2.80 \times 10^{-5}$ and $6.16 \times 10^{-4} \mathrm{~m} / \mathrm{s}$, where the latter is 21 -fold higher than the former. For the fluctuation period of $20000 \mathrm{~s}$, the average flow velocities 
increase slightly from $2.80 \times 10^{-5}$ to $3.80 \times 10^{-5} \mathrm{~m} / \mathrm{s}$ as amplitude increases from 0.14 to 0.19 $\mathrm{m}$. As mentioned earlier, the capillary pressure and soil water content do not have sufficient time to respond to watertable fluctuations for the experiments with a shorter fluctuation period. As a consequence, the time taking from a given saturation to the same saturation during a period of watertable fluctuation (time to reach equilibrium) is shorter, which further leads to a smaller $\tau$ at a given water saturation. In addition, when the fluctuation amplitude increases, the time needed to reach equilibrium is also shorter due to increasing flow velocity. Intrinsically, the flow velocity increases with increasing fluctuation amplitude or decreasing fluctuation period, which results in a reduction of time needed to reach equilibrium. In summary, the values of $\tau$ are dependent on the flow velocity.

To examine if different methods yield the same estimate given some variability in the data, we adopted Barenblatt's approach to obtain $\tau$ and estimate redistribution time $\tau_{b}$ for different watertable fluctuations. The Barenblatt curves are not monotonic is because the term $d P_{c}^{s t a} / d S_{w}$ is not monotonic and $\tau_{b}$ is a constant. Results for the watertable fluctuations with amplitudes of 0.14 and $0.19 \mathrm{~m}$ are respectively presented in Figures 12 and 13 with colored lines. Generally, the trend of $\tau$ values estimated from equation (8) is consistent with that estimated from equation (4). For the drying processes, the results calculated from equation (8) match well those from equation (4) for the longest period (20000 s). Nevertheless, there is a deviation between the results calculated from two equations, especially for the shorter periods. For the wetting processes, the results calculated from two equations are close each other for all experiments. Figure 14 presents the fitted $\tau_{b}$ values for 
all experiments. As can be clearly seen, the value of $\tau_{b}$ is larger for drying and decreases with decreasing fluctuation period. Moreover, the value of $\tau_{b}$ slightly decreases when the fluctuation amplitude varies from 0.14 to $0.19 \mathrm{~m}$.

\section{Conclusions}

A total of 28 experiments was conducted to investigate watertable fluctuation-induced variability in the WRC. These experiments cover a wide range of watertable fluctuations, involving three different amplitudes and 10 periods for the two lowest amplitudes and eight periods for the third. Two repeated measurements were carried out for each experiment to ensure reproducibility. Results show that both the response of capillary pressure and soil water content lag behind the watertable fluctuations, especially at locations far from the watertable and for shorter periods. For a longer fluctuation period, there is a location above which the capillary pressure keeps the same minimum value and hence the assumption of hydrostatic capillary pressure distribution only applies for areas from the watertable to this location. However, the hydrostatic capillary pressure distribution is not maintained for the shorter fluctuation period since the capillary pressure does not have sufficient time to respond to the watertable fluctuations.

Moreover, the WRC measured under watertable fluctuations deviates from that measured under static conditions depending on both the fluctuation amplitude and period. The shorter the fluctuation amplitude and period are, the smaller the extent of the dynamic hysteretic loop. The air-entry pressure under dynamic conditions is considerably larger than that under static conditions, and it first increases and then decreases with decreasing fluctuation period. Fitting 
the VG model to experimental data shows that $\alpha$ first decreases and then increases with decreasing fluctuation period. This is consistent with the air-entry pressure since the air-entry pressure is inversely proportional to $\alpha$.

A strong dependence of dynamic capillary coefficient $\tau$ on saturation was found for both drying and wetting. Generally, the magnitude of $\tau$ increases with decreasing saturation. The relationship between $\tau$ and saturation $S_{w}$ is nonunique, even for the drying and wetting of a given sand and watertable fluctuation, suggesting a hysteretic $\tau$. Moreover, the values of $\tau$ are rate-dependent and decrease with an increase of flow velocity. The nonunique $\tau-S_{w}$ relationship during watertable fluctuations could be caused by different pore water redistribution processes and the hysteresis in the WRC. Further studies are necessary to reveal the pore water redistribution process during watertable fluctuation and its relations with $\tau$.

This study focused on examining the effects of watertable fluctuation on the WRC through a series of $1 \mathrm{D}$ sand column experiments. In reality, the watertable fluctuation is expected to occur in $2 \mathrm{D}$ or $3 \mathrm{D}$, e.g., for coastal aquifers. Therefore, more $2 \mathrm{D}$ or $3 \mathrm{D}$ experiments are required to investigate the spatial variability of the WRC induced by watertable fluctuations. To better understand the behavior of the dynamic capillary coefficient, scale effects and longer-period fluctuations should be considered in the future work. As Cartwright (2014) and Shoushtari et al. (2017) have pointed out, the experiments conducted in the present study cannot be predicted accurately using existing numerical models. Our experimental findings may still play an important role in facilitating the further 
development of numerical models to well predict the WRC subjected to short-period fluctuations.

\section{Acknowledgments}

This research was supported by the National Key R\&D Program of China (2018YFC0407201), the Fundamental Research Funds for the Central Universities (2019B80714), the Postgraduate Research \& Practice Innovation Program of Jiangsu Province (SJKY19-0503) and National Natural Science Foundation of China (41807178, 51979095). The first author thanks the China Scholarship Council for financial support (201906710039), and Dr. Xindi Chen for helping measure the sand's particle size distribution. The experimental data are available in the Supporting Information. The authors appreciate constructive comments from the associate editor and three anonymous reviewers, which led to significant improvement of the paper. 


\section{References}

Barry, D. A., Barry, S., \& Parlange, J.-Y. (1996). Capillarity correction to periodic solutions of the shallow flow approximation. In Mixing in estuaries and coastal seas (pp. 496510). Washington, DC: American Geophysical Union. doi:10.1029/CE050p0496

Bittelli, M., \& Flury, M. (2009). Errors in water retention curves determined with pressure plates. Soil Science Society of America Journal, 73(5), 1453-1460. doi:10.2136/sssaj2008.0082

Bottero, S., Hassanizadeh, S. M., Kleingeld, P., \& Heimovaara, T. J. (2011). Nonequilibrium capillarity effects in two-phase flow through porous media at different scales. Water Resources Research, 47(10). doi:10.1029/2011WR010887

Brakenhoff, L. B., Smit, Y., Donker, J. J., \& Ruessink, G. (2019). Tide-induced variation in beach surface moisture: Observations and modelling. Earth Surface Processes and Landforms, 44(1), 317-330. doi:10.1002/esp.4493

Burdine, N. (1953). Relative permeability calculations from pore size distribution data. Journal of Petroleum Technology, 5(3), 71-78. doi:10.2118/225-G

Camps-Roach, G., O’Carroll, D. M., Newson, T. A., Sakaki, T., \& Illangasekare, T. H. (2010). Experimental investigation of dynamic effects in capillary pressure: Grain size dependency and upscaling. Water Resources Research, 46(8). doi:10.1029/2009WR008881

Cartwright, N. (2014). Moisture-pressure dynamics above an oscillating water table. Journal of Hydrology, 512, 442-446. doi:10.1016/j.jhydrol.2014.03.024

Cartwright, N., Nielsen, P., \& Li, L. (2004). Experimental observations of watertable waves in an unconfined aquifer with a sloping boundary. Advances in Water Resources, 27(10), 991-1004. doi:10.1016/j.advwatres.2004.08.006

Chin, K.-B., Leong, E.-C., \& Rahardjo, H. (2010). A simplified method to estimate the soilwater characteristic curve. Canadian Geotechnical Journal, 47(12), 1382-1400. doi:10.1139/T10-033

Corey, A. T. (1994). Mechanics of immiscible fluids in porous media. USA: Water Resources 
Publication, Highlands Ranch, Colorado 80126-0026.

Cornelis, W. M., Ronsyn, J., Van Meirvenne, M., \& Hartmann, R. (2001). Evaluation of pedotransfer functions for predicting the soil moisture retention curve. Soil Science Society of America Journal, 65(3), 638-648. doi:10.2136/sssaj2001.653638x

Crescimanno, G., \& Iovino, M. (1995). Parameter estimation by inverse method based on one-step and multi-step outflow experiments. Geoderma, 68(4), 257-277. doi:10.1016/0016-7061(95)00049-8

Diamantopoulos, E., \& Durner, W. (2012). Dynamic nonequilibrium of water flow in porous media: A review. Vadose Zone Journal, 11(3). doi:10.2136/vzj2011.0197

Diamantopoulos, E., Durner, W., Iden, S., Weller, U., \& Vogel, H.-J. (2015). Modeling dynamic non-equilibrium water flow observations under various boundary conditions. Journal of Hydrology, 529, 1851-1858. doi:10.1016/j.jhydrol.2015.07.032

Diamantopoulos, E., Iden, S., \& Durner, W. (2012). Inverse modeling of dynamic nonequilibrium in water flow with an effective approach. Water Resources Research, 48(3). doi:10.1029/2011WR010717

Durner, W., \& Iden, S. C. (2011). Extended multistep outflow method for the accurate determination of soil hydraulic properties near water saturation. Water Resources Research, 47(8). doi:10.1029/2011WR010632

Guarracino, L. (2007). Estimation of saturated hydraulic conductivity $K_{S}$ from the van Genuchten shape parameter $\alpha$. Water Resources Research, 43(11). doi:10.1029/2006WR005766

Haghverdi, A., Öztürk, H. S., \& Durner, W. (2018). Measurement and estimation of the soil water retention curve using the evaporation method and the pseudo continuous pedotransfer function. Journal of Hydrology, 563, 251-259. doi:10.1016/j.jhydrol.2018.06.007

Hassanizadeh, S. M., Celia, M. A., \& Dahle, H. K. (2002). Dynamic effect in the capillary pressure-saturation relationship and its impacts on unsaturated flow. Vadose Zone Journal, 1(1), 38-57. doi:10.2136/vzj2002.3800 
Hassanizadeh, S. M., \& Gray, W. G. (1990). Mechanics and thermodynamics of multiphase flow in porous media including interphase boundaries. Advances in Water Resources, 13(4), 169-186. doi:10.1016/0309-1708(90)90040-B

Hoitink, A., \& Jay, D. A. (2016). Tidal river dynamics: Implications for deltas. Reviews of Geophysics, 54(1), 240-272. doi:10.1002/2015RG000507

Joekar-Niasar, V., Hassanizadeh, S. M., \& Dahle, H. (2010). Non-equilibrium effects in capillarity and interfacial area in two-phase flow: Dynamic pore-network modelling. Journal of Fluid Mechanics, 655, 38-71. doi:10.1017/S0022112010000704

Juanes, R. (2008). Nonequilibrium effects in models of three-phase flow in porous media. Advances in Water Resources, 31(4), 661-673. doi:10.1016/j.advwatres.2007.12.005

Kong, J., Shen, C. J., Xin, P., Song, Z., Li, L., Barry, D. A., Jeng, D.-S., Stagnitti, F., Lockington, D. A., \& Parlange, J.-Y. (2013). Capillary effect on water table fluctuations in unconfined aquifers. Water Resources Research, 49(5), 3064-3069. doi:10.1002/wrcr.20237

Kong, J., Xin, P., Hua, G.-F., Luo, Z.-Y., Shen, C.-J., Chen, D., \& Li, L. (2015). Effects of vadose zone on groundwater table fluctuations in unconfined aquifers. Journal of Hydrology, 528, 397-407. doi:10.1016/j.jhydrol.2015.06.045

Kool, J., \& Parker, J. C. (1987). Development and evaluation of closed-form expressions for hysteretic soil hydraulic properties. Water Resources Research, 23(1), 105-114. doi:10.1029/WR023i001p00105

Kool, J., Parker, J., \& van Genuchten, M. T. (1985). Determining soil hydraulic properties from one-step outflow experiments by parameter estimation: I. Theory and numerical studies 1. Soil Science Society of America Journal, 49(6), 1348-1354. doi:10.2136/sssaj1985.03615995004900060004x

Larsen, L. G., Harvey, J. W., \& Maglio, M. M. (2014). Dynamic hyporheic exchange at intermediate timescales: Testing the relative importance of evapotranspiration and flood pulses. Water Resources Research, 50(1), 318-335. doi:10.1002/2013WR014195

Li, J., He, X., Li, C., Du, Y., Li, Y., Xia, J., Gao, J., Yang, Y., \& Li, Y. (2019). Factors 
influencing dynamic non-equilibrium effects in drainage processes of an air-water two-phase fine sandy medium. Water Resources Research, 55(3), 2232-2256. doi:10.1029/2018WR023034

Li, L., Barry, D., Parlange, J.-Y., \& Pattiaratchi, C. (1997a). Beach water table fluctuations due to wave run-up: Capillarity effects. Water Resources Research, 33(5), 935-945. doi:10.1029/96WR03946

Li, L., Barry, D., \& Pattiaratchi, C. (1997b). Numerical modelling of tide-induced beach water table fluctuations. Coastal Engineering, 30(1-2), 105-123. doi:10.1016/S03783839(96)00038-5

Li, L., Barry, D. A., Stagnitti, F., \& Parlange, J.-Y. (2000a). Groundwater waves in a coastal aquifer: A new governing equation including vertical effects and capillarity. Water Resources Research, 36(2), 411-420. doi:10.1029/1999WR900307

Li, L., Barry, D. A., Stagnitti, F., Parlange, J.-Y., \& Jeng, D.-S. (2000b). Beach water table fluctuations due to spring-neap tides: Moving boundary effects. Advances in Water Resources, 23(8), 817-824. doi:10.1016/S0309-1708(00)00017-8

Li, P., \& Berkowitz, B. (2018). Controls on interactions between resident and infiltrating waters in porous media. Advances in Water Resources, 121, 304-315. doi:10.1016/j.advwatres.2018.09.002

Likos, W. J., Lu, N., \& Godt, J. W. (2014). Hysteresis and uncertainty in soil water-retention curve parameters. Journal of Geotechnical and Geoenvironmental Engineering, 140(4), 04013050. doi:10.1061/(ASCE)GT.1943-5606.0001071

Lo, W. C., Yang, C. C., Hsu, S. Y., Chen, C. H., Yeh, C. L., \& Hilpert, M. (2017). The dynamic response of the water retention curve in unsaturated soils during drainage to acoustic excitations. Water Resources Research, 53(1), 712-725. doi:10.1002/2016WR018833

Luo, Z., Kong, J., Ji, Z., Zhou., C., Yao, Y. \& Han, X. (2019a). Device and method for measuring dynamic soil water retention curve in laboratory (in Chinese). http://www2.soopat.com/Patent/201910424936

Luo, Z., Kong, J., Shen, C., Lu, C., Hua, G., Zhao, Z., Zhao, H., \& Li, L. (2019b). Evaluation 
and application of the modified van Genuchten function for unsaturated porous media. Journal of Hydrology, 571, 279-287. doi:10.1016/j.jhydrol.2019.01.051

Luo, Z., Shen, C., Kong, J., Hua, G., Gao, X., Zhao, Z., Zhao, H., \& Li, L. (2018). Effects of unsaturated flow on hillslope recession characteristics. Water Resources Research, 54(3), 2037-2056. doi:10.1002/2017WR022257

Jin, G., Guan, W., Shen, C., Xie, T., Tang, H., Wang, G., Jiang, Q. \& Li, L. (2014). Tidal wave generator and its use method (in Chinese).

http://dbpub.cnki.net/grid2008/dbpub/detail.aspx?dbname=SCPD\&filename=CN1042 97139A

Mirzaei, M., \& Das, D. B. (2013). Experimental investigation of hysteretic dynamic effect in capillary pressure-saturation relationship for two-phase flow in porous media. AIChE Journal, 59(10), 3958-3974. doi:10.1002/aic.14121

Mualem, Y. (1976). A new model for predicting the hydraulic conductivity of unsaturated porous media. Water Resources Research, 12(3), 513-522.

doi:10.1029/WR012i003p00513

Nilsson, C., Reidy, C. A., Dynesius, M., \& Revenga, C. (2005). Fragmentation and flow regulation of the world's large river systems. Science, 308(5720), 405-408. doi:10.1126/science.1107887

O’Carroll, D. M., Phelan, T. J., \& Abriola, L. M. (2005). Exploring dynamic effects in capillary pressure in multistep outflow experiments. Water Resources Research, 41(11). doi:10.1029/2005WR004010

Or, D., Lehmann, P., \& Assouline, S. (2015). Natural length scales define the range of applicability of the Richards equation for capillary flows. Water Resources Research, 51(9), 7130-7144. doi:10.1002/2015WR017034

Peters, A. (2013). Simple consistent models for water retention and hydraulic conductivity in the complete moisture range. Water Resources Research, 49(10), 6765-6780. doi:10.1002/wrcr.20548

Reatto, A., da Silva, E. M., Bruand, A., Martins, E. S., \& Lima, J. E. F. W. (2008). Validity of the centrifuge method for determining the water retention properties of tropical soils. 
Soil Science Society of America Journal, 72(6), 1547-1553.

doi: $10.2136 /$ sssaj2007.0355N

Robinson, C. E., Xin, P., Santos, I. R., Charette, M. A., Li, L., \& Barry, D. A. (2018).

Groundwater dynamics in subterranean estuaries of coastal unconfined aquifers:

Controls on submarine groundwater discharge and chemical inputs to the ocean.

Advances in Water Resources, 115, 315-331. doi:10.1016/j.advwatres.2017.10.041

Rupp, D. E., \& Selker, J. S. (2006). Information, artifacts, and noise in dQ/dt - Q recession analysis. Advances in Water Resources, 29(2), 154-160.

doi:10.1016/j.advwatres.2005.03.019

Sakaki, T., O’Carroll, D. M., \& Illangasekare, T. H. (2010). Direct quantification of dynamic effects in capillary pressure for drainage-wetting cycles. Vadose Zone Journal, 9(2), 424-437. doi:10.2136/vzj2009.0105

Schultze, B., Ippisch, O., Huwe, B., \& Durner, W. (1997). Dynamic nonequilibrium during unsaturated water flow. Paper presented at the Proceedings of the International Workshop on Characterization and Measurement of the HydraulicPproperties of Unsaturated Porous Media. M. Th. van Genuchten, F. J. Leij, and L. Wu (eds.) Proc. Int. Workshop on Characterization and Measurement of the Hydraulic Properties of Unsaturated Porous Media, October 22-24, 1997, University of California, Riverside, CA., 1999. http://www.soil.tu-bs.de/download/downloads/pubs/1999.Schultzeetal.Dynamic.pdf

Shen, C., Zhang, C., Xin, P., Kong, J., \& Li, L. (2018). Salt dynamics in coastal marshes: Formation of hypersaline zones. Water Resources Research, 54(5), 3259-3276. doi:10.1029/2017WR022021

Shoushtari, S. M. H. J., Cartwright, N., Nielsen, P., \& Perrochet, P. (2016). The effects of oscillation period on groundwater wave dispersion in a sandy unconfined aquifer: Sand flume experiments and modelling. Journal of Hydrology, 533, 412-420. doi:10.1016/j.jhydrol.2015.12.032

Shuai, P., Cardenas, M. B., Knappett, P. S., Bennett, P. C., \& Neilson, B. T. (2017). 
Denitrification in the banks of fluctuating rivers: The effects of river stage amplitude, sediment hydraulic conductivity and dispersivity, and ambient groundwater flow. Water Resources Research, 53(9), 7951-7967. doi:10.1002/2017WR020610

Solone, R., Bittelli, M., Tomei, F., \& Morari, F. (2012). Errors in water retention curves determined with pressure plates: Effects on the soil water balance. Journal of Hydrology, 470, 65-74. doi:10.1016/j.jhydrol.2012.08.017

Stauffer, F. (1978). Time dependence of the relations between capillary pressure, water content and conductivity during drainage of porous media. Paper presented at the IAHR Symposium on Scale Effects in Porous Media, Thessaloniki, Greece 29 Aug. - 1 Sept. 1978, IAHR, Madrid, Spain.

Topp, G., Klute, A., \& Peters, D. (1967). Comparison of water content-pressure head data obtained by equilibrium, steady-state, and unsteady-state methods 1. Soil Science Society of America Journal, 31(3), 312-314. doi:10.2136/ sssaj1967.03615995003100030009x

van Genuchten, M. T. (1980). A closed-form equation for predicting the hydraulic conductivity of unsaturated soils. Soil Science Society of America Journal, 44(5), 892898. doi:10.2136/sssaj1980.03615995004400050002x

Xin, P., Robinson, C., Li, L., Barry, D. A., \& Bakhtyar, R. (2010). Effects of wave forcing on a subterranean estuary. Water Resources Research, 46(12). doi:10.1029/2010WR009632

Xin, P., Wang, S. S., Robinson, C., Li, L., Wang, Y. G., \& Barry, D. A. (2014). Memory of past random wave conditions in submarine groundwater discharge. Geophysical Research Letters, 41(7), 2401-2410. doi:10.1002/2014GL059617

Xin, P., Wang, S. S., Shen, C., Zhang, Z., Lu, C., \& Li, L. (2018). Predictability and quantification of complex groundwater table dynamics driven by irregular surface water fluctuations. Water Resources Research, 54(3), 2436-2451. doi:10.1002/2017WR021761

Yu, X., Xin, P., \& Lu, C. (2019). Seawater intrusion and retreat in tidally-affected unconfined 
aquifers: Laboratory experiments and numerical simulations. Advances in Water Resources, 132, 103393. doi:10.1016/j.advwatres.2019.103393

Zhuang, L., Hassanizadeh, S. M., Qin, C. Z., \& de Waal, A. (2017). Experimental investigation of hysteretic dynamic capillarity effect in unsaturated flow. Water Resources Research, 53(11), 9078-9088. doi:10.1002/2017WR020895 
Table 1. Hydraulic properties of the sand used in the experiments ${ }^{\mathrm{a}}$.

\begin{tabular}{|c|c|c|c|c|c|c|}
\hline$K_{s}(\mathrm{~m} / \mathrm{s})$ & $\alpha_{d}\left(\mathrm{~m}^{-1}\right)$ & $n_{d}$ & $\alpha_{w}\left(\mathrm{~m}^{-1}\right)$ & $n_{w}$ & $\theta_{s}$ & $\theta_{r}$ \\
\hline $4.57 \times 10^{-3}$ & 7.5 & 4.298 & 15 & 4.298 & 0.39 & 0.01 \\
\hline
\end{tabular}

${ }^{\mathrm{a}} K_{s}$ is the saturated hydraulic conductivity; $\theta_{s}$ and $\theta_{r}$ are the saturated and residual soil water content, respectively. According to the method of Kool and Parker (1987), $n_{w}=n_{d}$ and $\alpha_{w}=\gamma \alpha_{d}$ with $\gamma$ usually chosen equal 2 . 


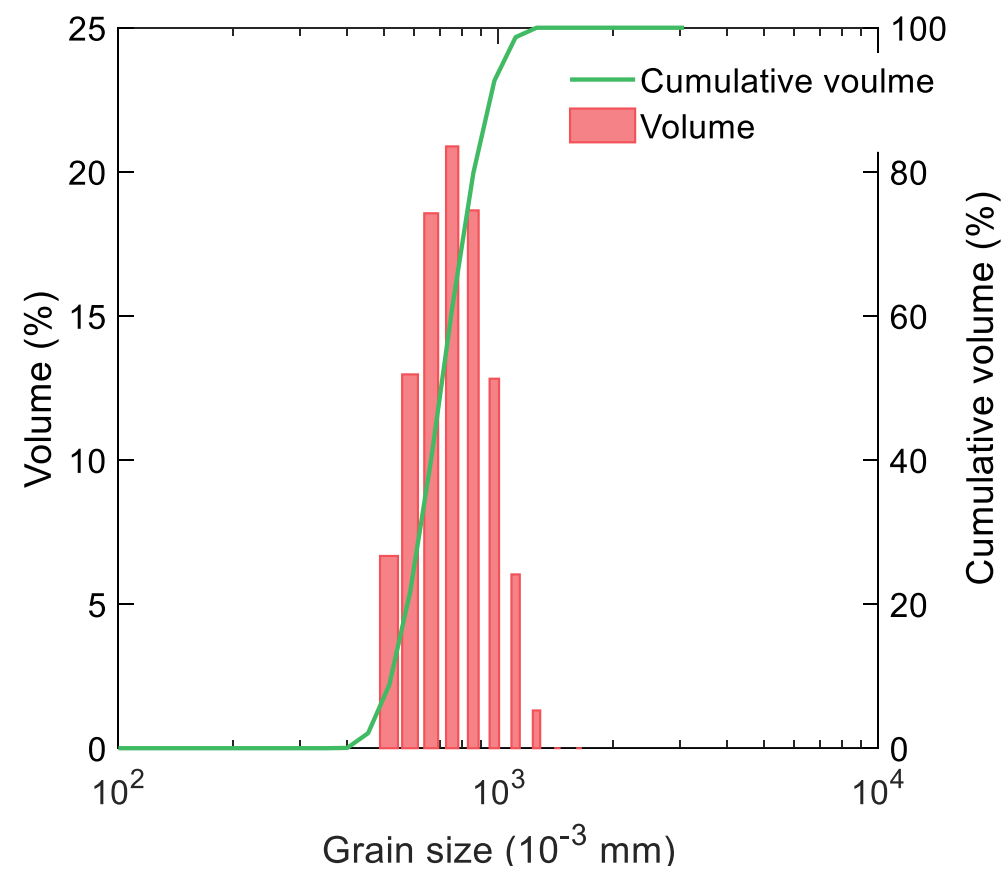

Figure 1. Particle size distribution of the sand used in the experiments. 
(a)

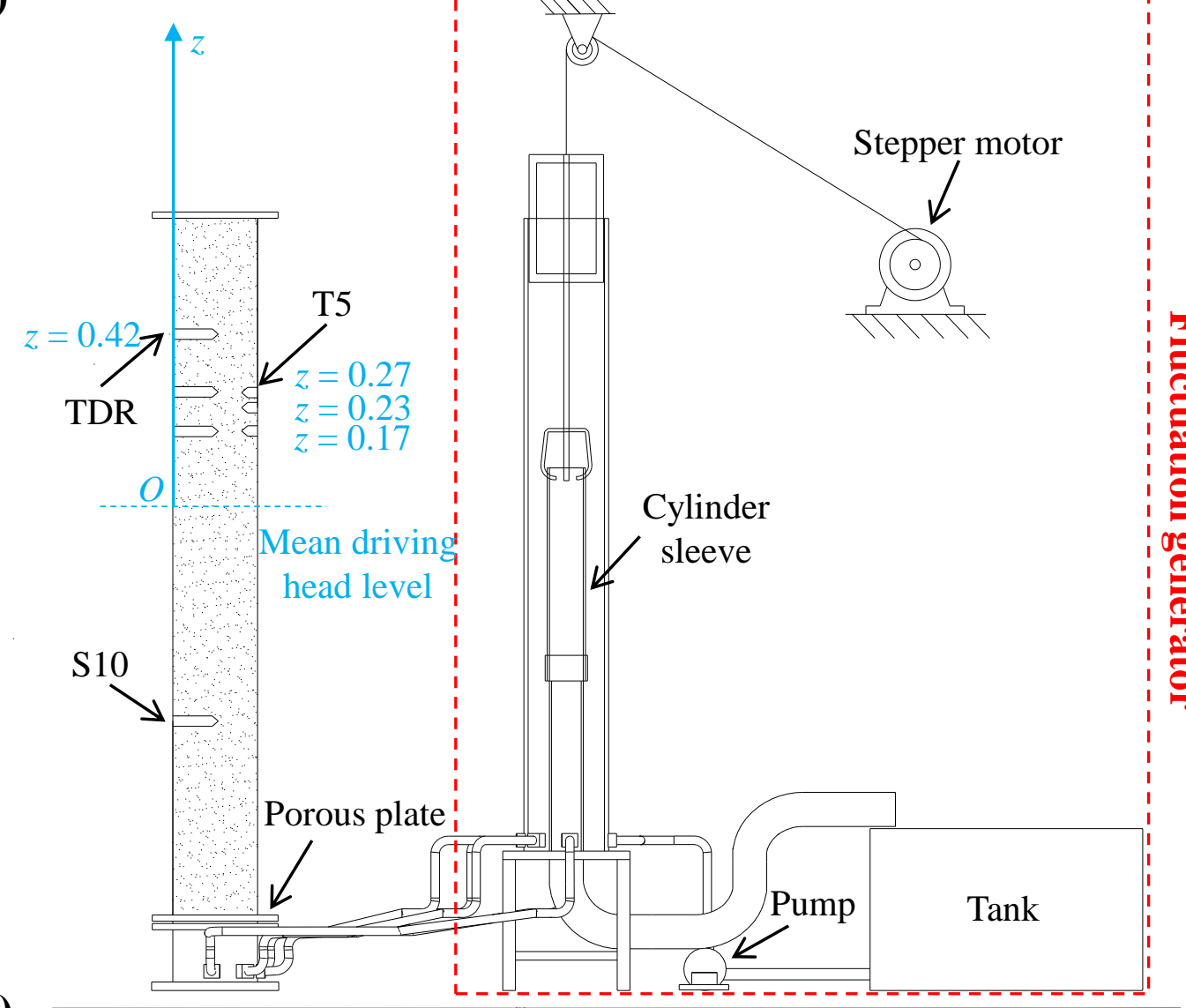

(b)

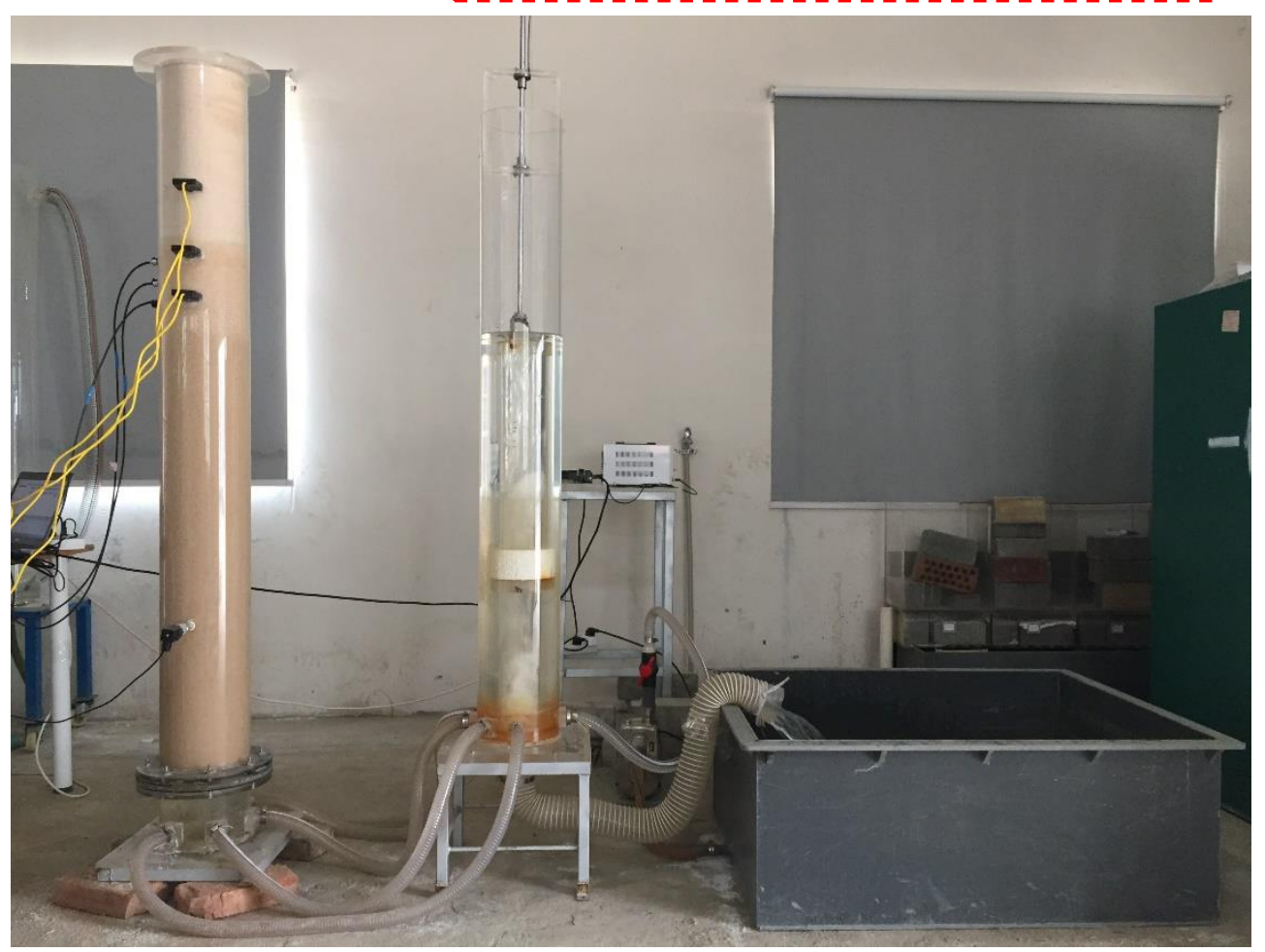

Figure 2. (a) Schematic and (b) photo of the experimental apparatus. Note that the unit in (a) is $\mathrm{m}$. The apparatus consists of a sand column and a fluctuation generator. A stepper motor 
was connected using a steel cable to the cylinder sleeve in the fluctuation generator, which changes the watertable. Three Time Domain Reflectometry (TDR) probes and three UMS T5 tensiometers were respectively used to measure the soil water content and capillary pressure. The watertable fluctuation imposed at the sand column base was measured through a highresolution piezometer S10. All the instruments were connected to a data logger. 
(a)

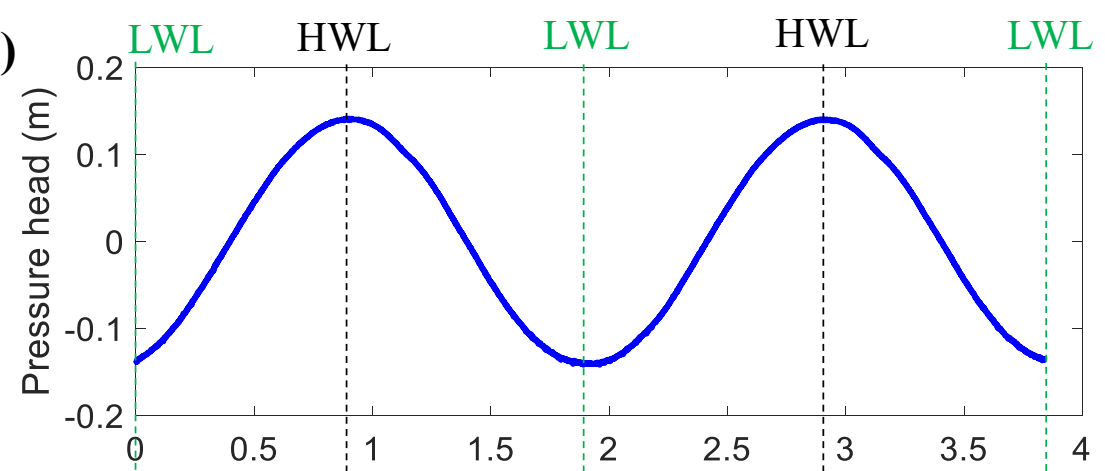

(b)

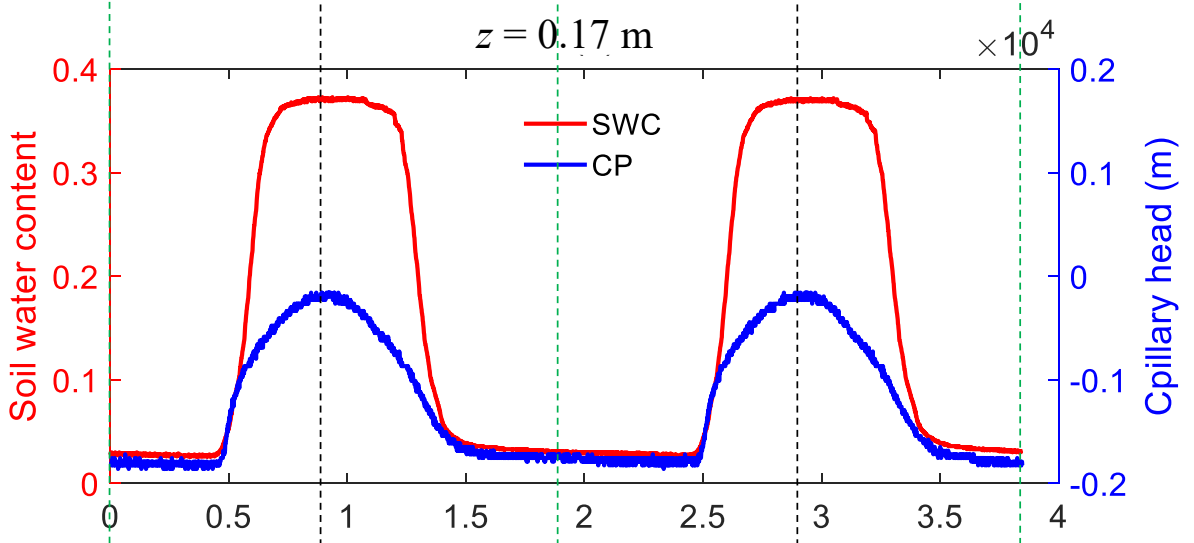

(c)

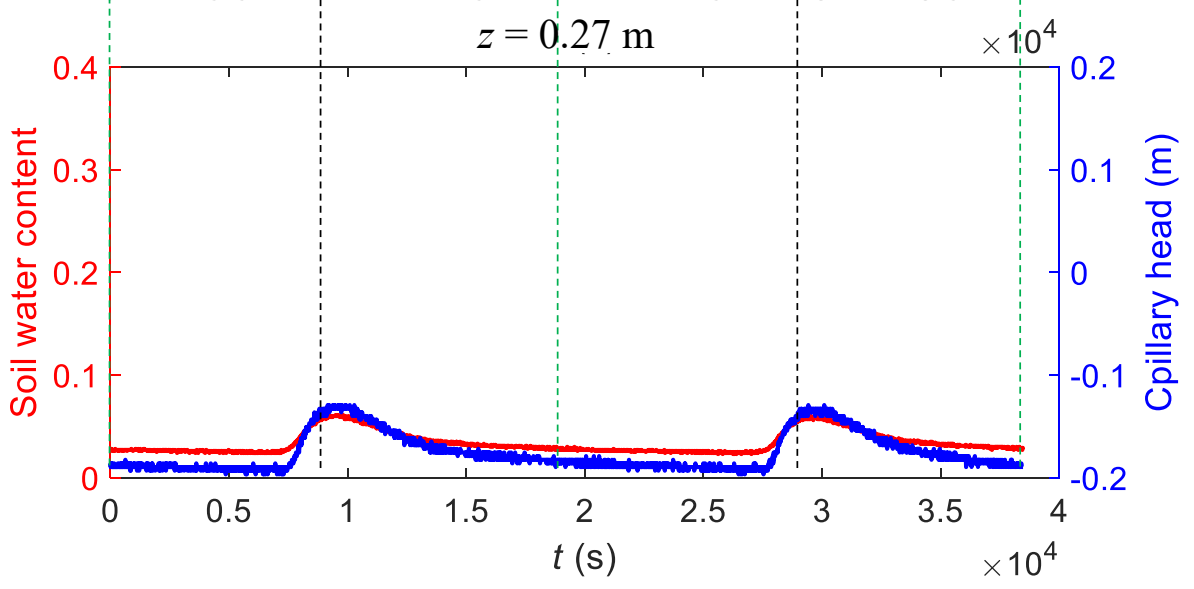

Figure 3. Responses of soil water content and capillary pressure at (b) $z=0.17 \mathrm{~m}$ and (c) $z=$ $0.27 \mathrm{~m}$ to (a) the watertable fluctuation with an amplitude of $0.14 \mathrm{~m}$ and a period of $20000 \mathrm{~s}$. Note that SWC indicates the soil water content, CP represents the capillary pressure, and HWL and LWL denote the high and low water level, respectively. In addition, the legend in (c) is the same with (b). 


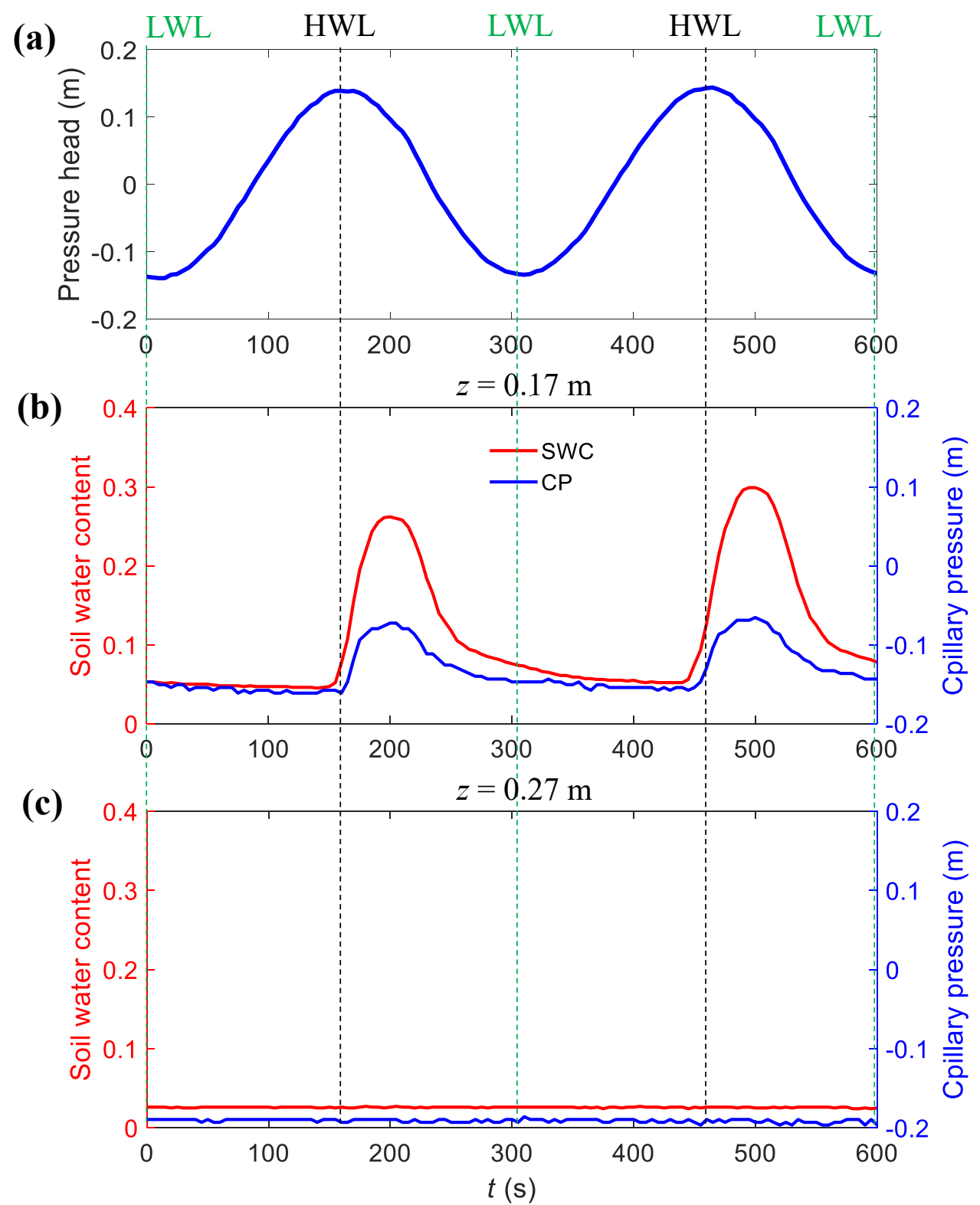

Figure 4. Responses of soil water content and capillary pressure at (b) $z=0.17 \mathrm{~m}$ and (c) $z=$ $0.27 \mathrm{~m}$ to (a) the watertable fluctuation with an amplitude of $0.14 \mathrm{~m}$ and a period of $299 \mathrm{~s}$. Note that SWC indicates the soil water content, CP represents the capillary pressure, and HWL and LWL denote the high and low water level, respectively. In addition, the legend in (c) is the same with (b). 


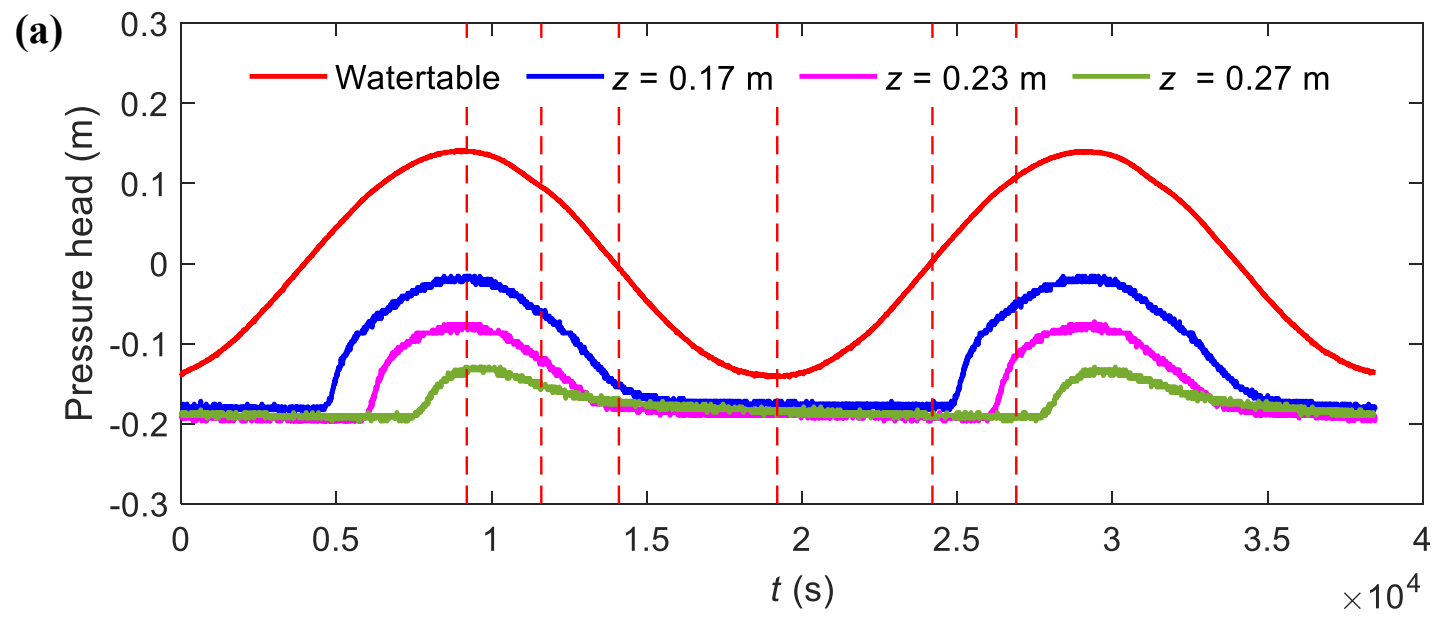

(b) $9200 \mathrm{~s}$

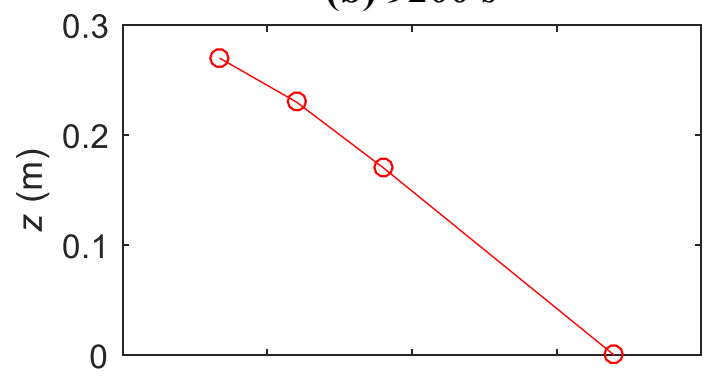

(c) $11600 \mathrm{~s}$

(d) $14100 \mathrm{~s}$

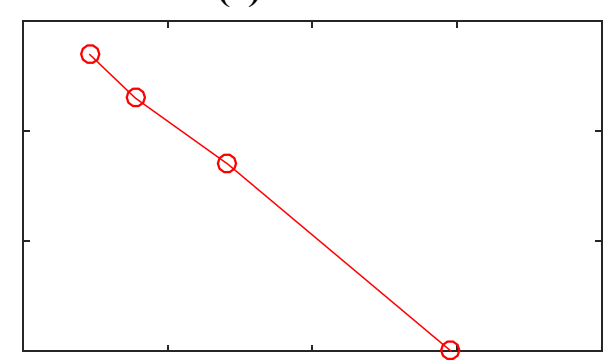

(e) $19200 \mathrm{~s}$

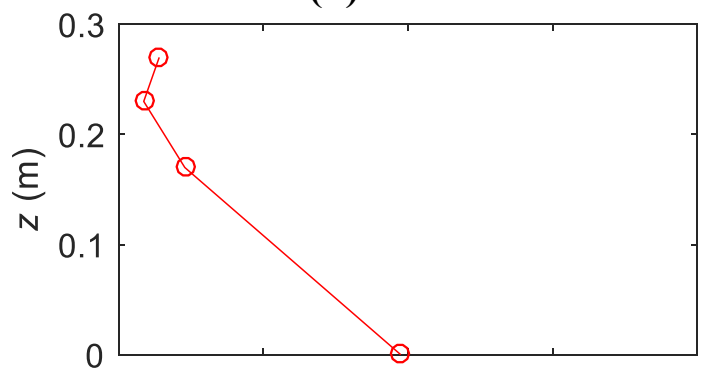

(f) $24200 \mathrm{~s}$
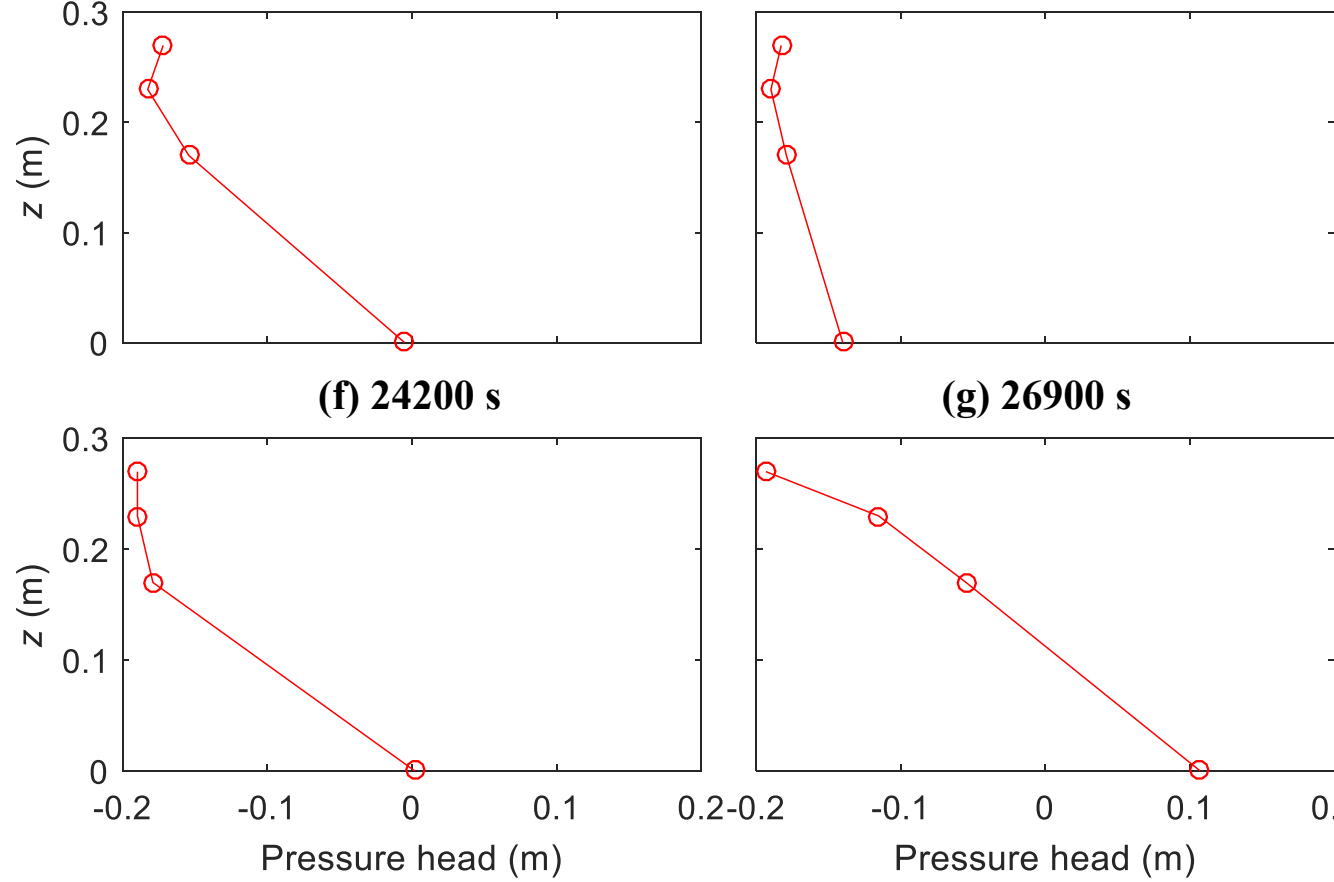

\section{(g) $26900 \mathrm{~s}$}

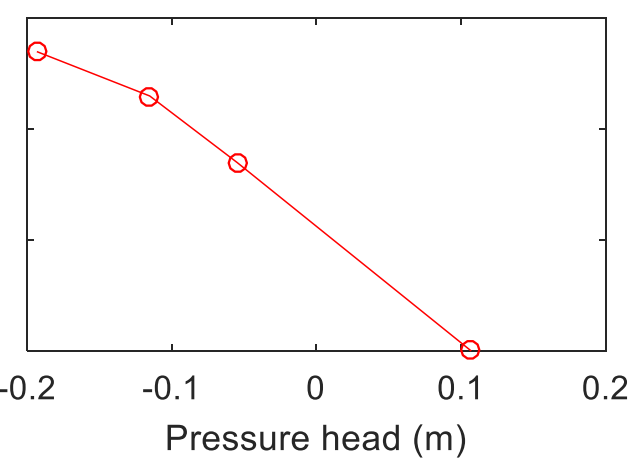

Figure 5. (a) Measured capillary pressure time series at three locations for the watertable fluctuation with amplitude of $0.14 \mathrm{~m}$ and period of $20000 \mathrm{~s}$, and (b-g) the vertical capillary pressure distribution at different times indicated by the red dashed lines in plot (a). 


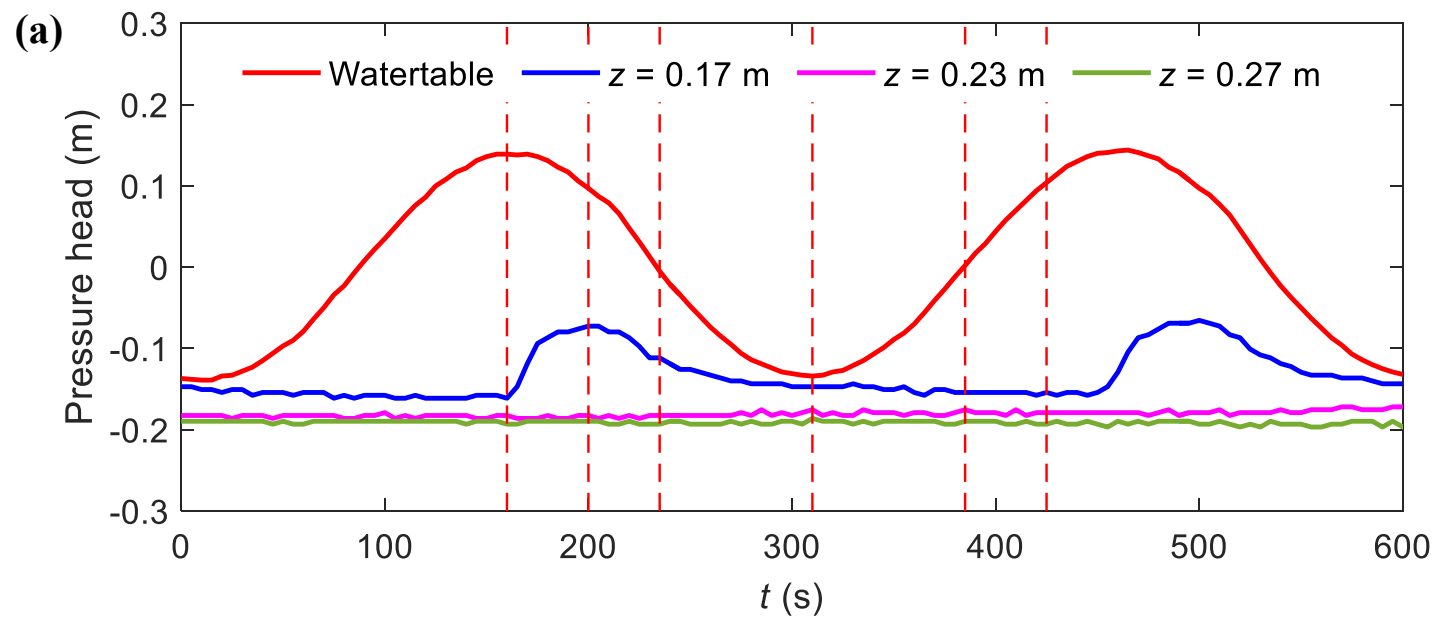

(b) $160 \mathrm{~s}$

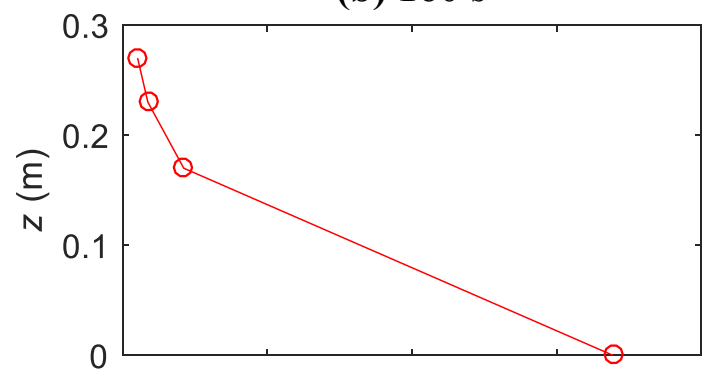

(c) $200 \mathrm{~s}$

(d) $235 \mathrm{~s}$

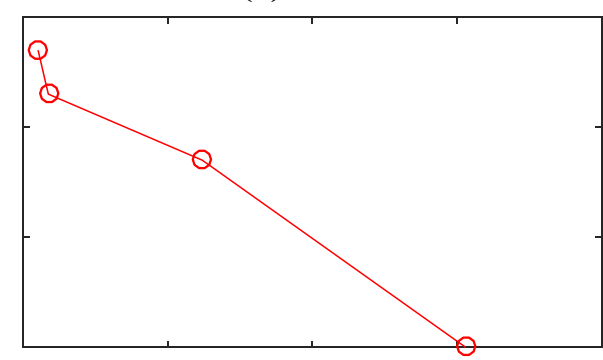

(e) $310 \mathrm{~s}$
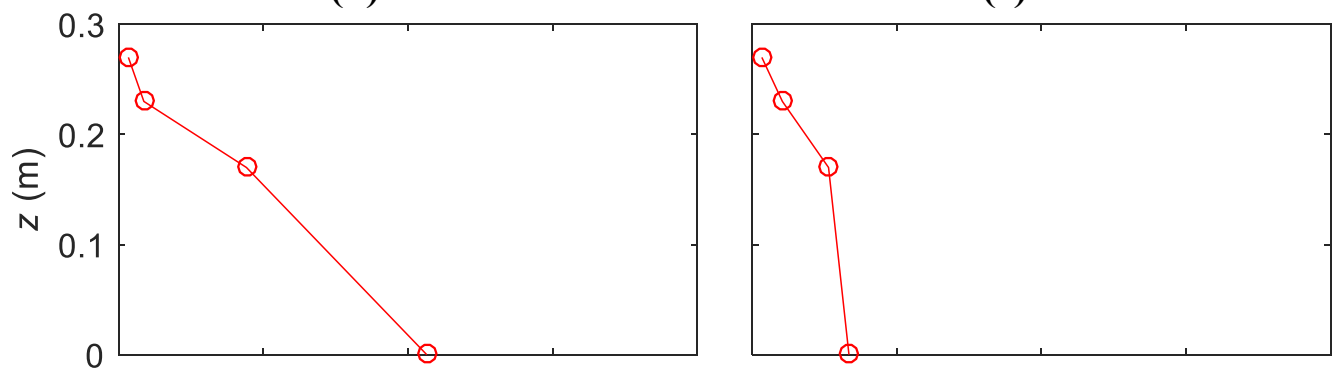

(f) $385 \mathrm{~s}$

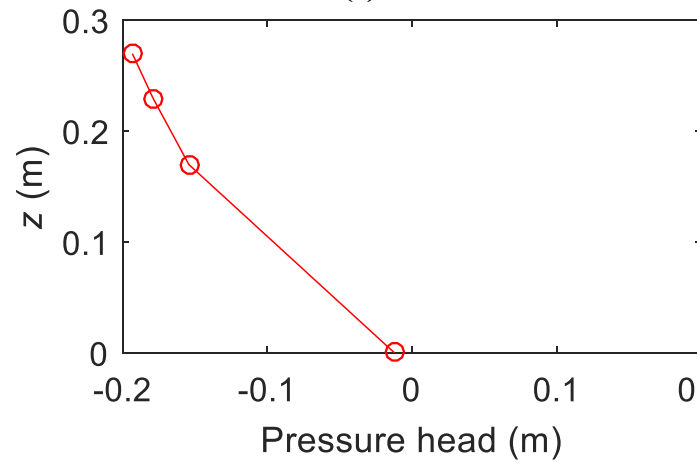

(g) $425 \mathrm{~s}$

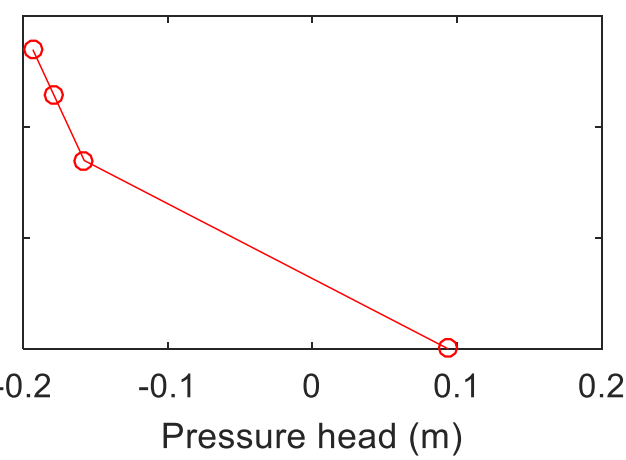

Figure 6. (a) Measured capillary pressure time series at three locations for the watertable fluctuation with amplitude of $0.14 \mathrm{~m}$ and period of $299 \mathrm{~s}$, and (b-g) the vertical capillary pressure distribution at different times indicated by the red dashed lines in plot (a). 
(a) $20000 \mathrm{~s}$

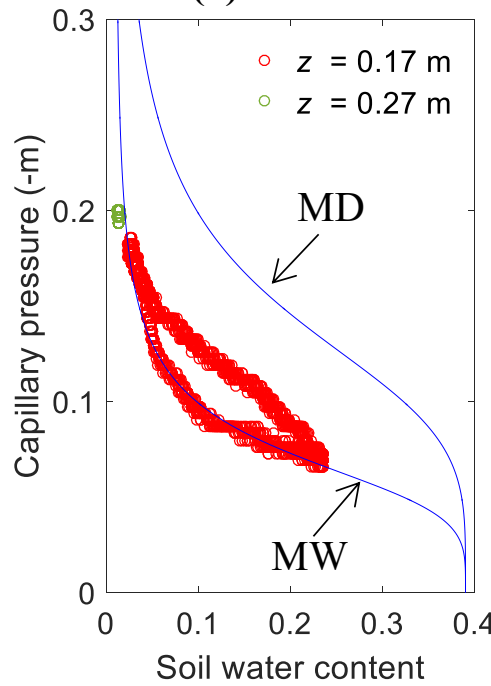

(d) $2857 \mathrm{~s}$

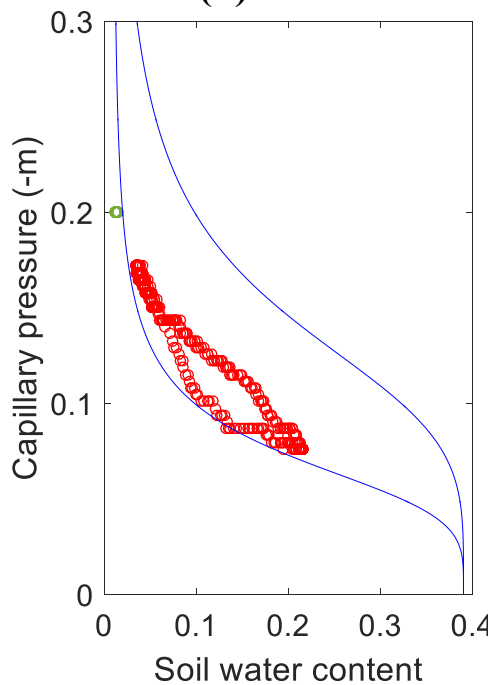

(g) $909 \mathrm{~s}$

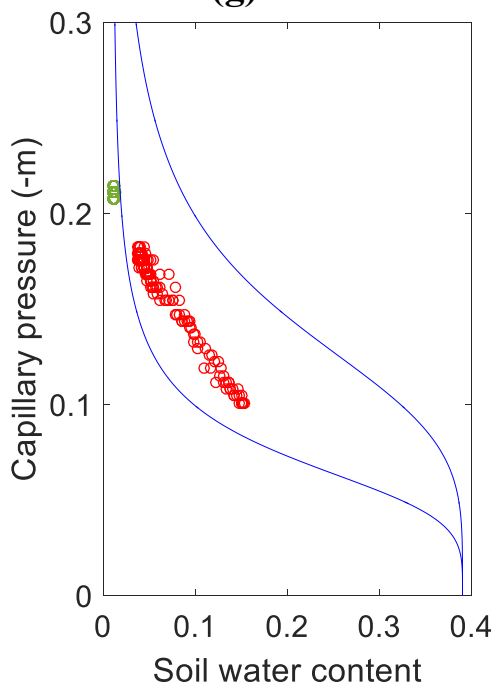

(b) $10000 \mathrm{~s}$

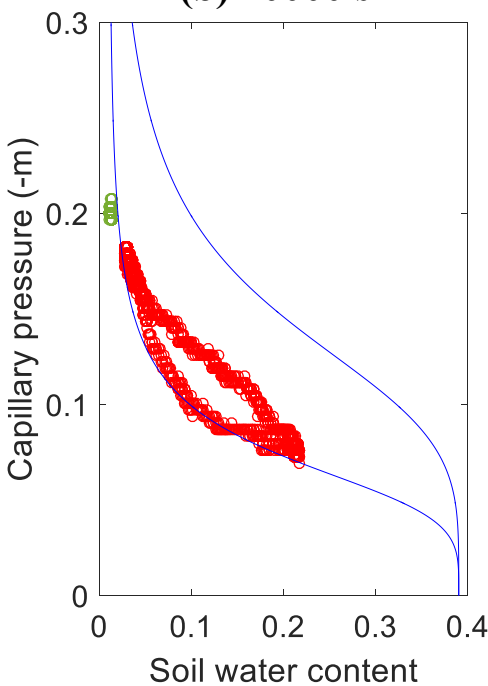

(e) $1818 \mathrm{~s}$

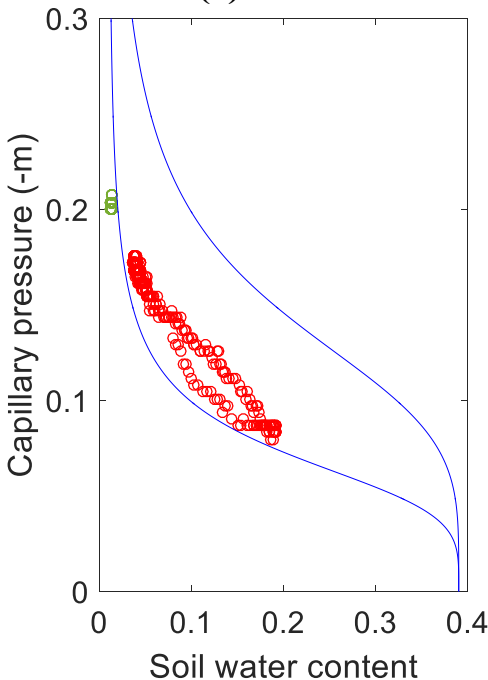

(h) $588 \mathrm{~s}$

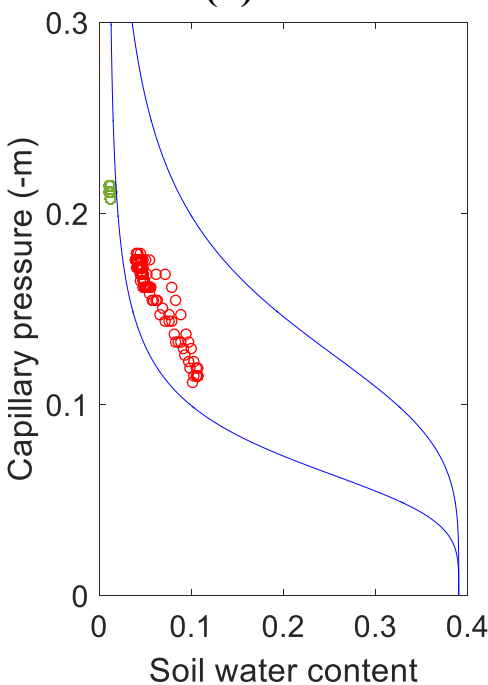

(c) $5000 \mathrm{~s}$

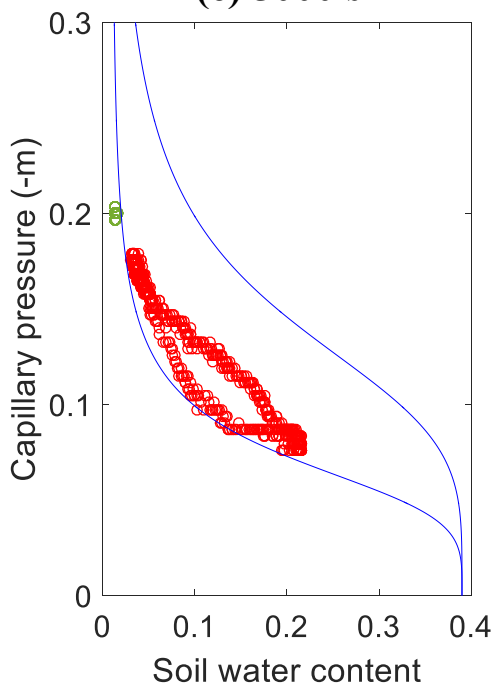

(f) $1250 \mathrm{~s}$

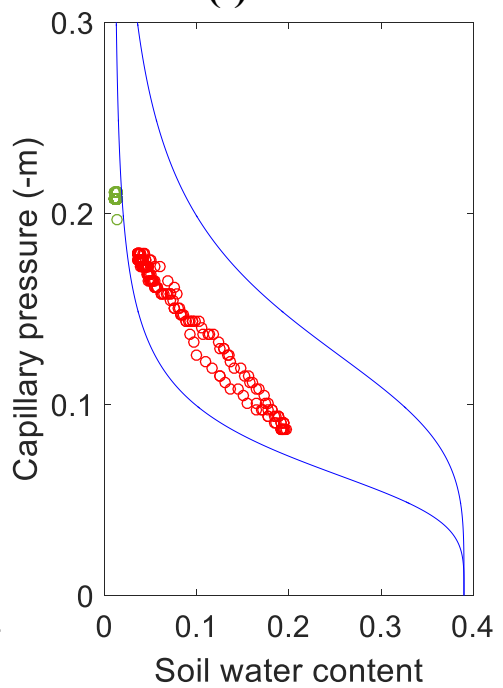

(i) $299 \mathrm{~s}$

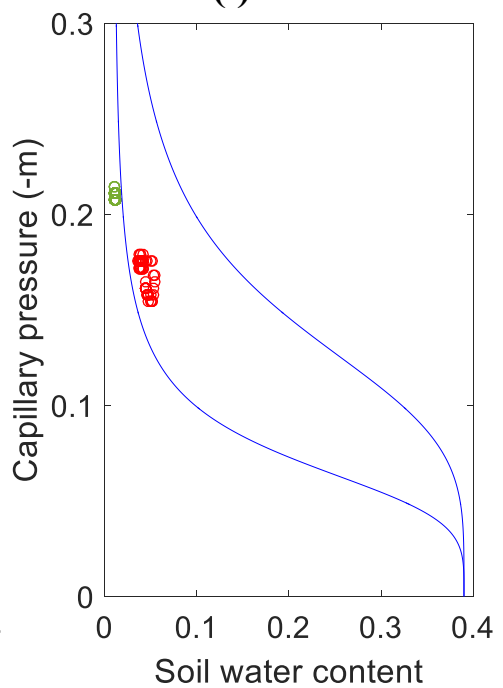

Figure 7. Measurements of the WRC at $z=0.17 \mathrm{~m}$ (red circles) and $z=0.27 \mathrm{~m}$ (green circles) for different watertable fluctuations having the same amplitude of $0.09 \mathrm{~m}$ but different periods 
as indicated. The blue lines represent the static WRC under drainage and imbibition conditions, i.e., static main drying (MD) and wetting (MW) curves. Note that the data presented in each panel were measured over a full fluctuation period. 
(a) $20000 \mathrm{~s}$

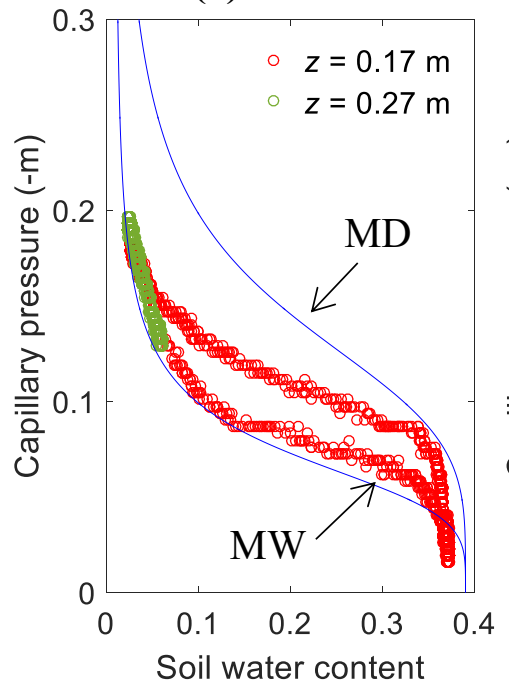

(d) $2857 \mathrm{~s}$

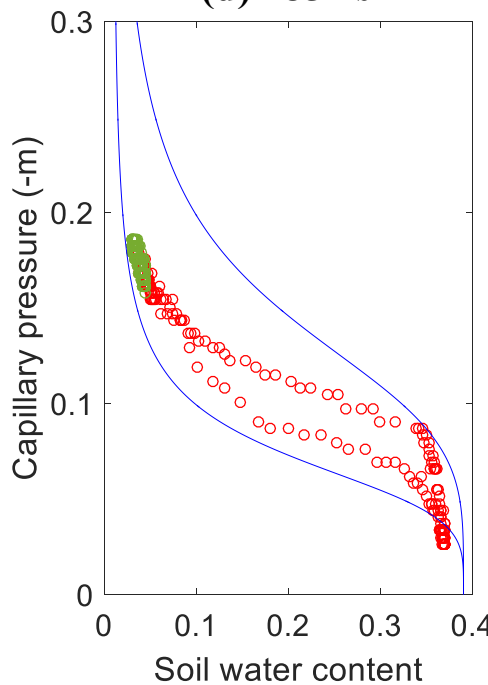

(g) $909 \mathrm{~s}$

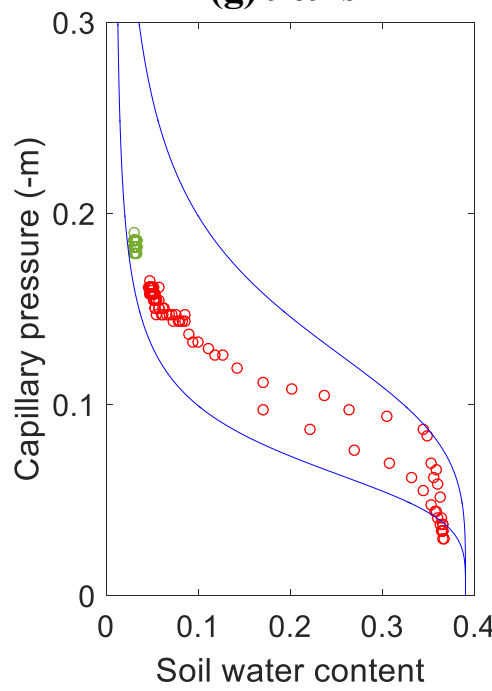

(b) $10000 \mathrm{~s}$

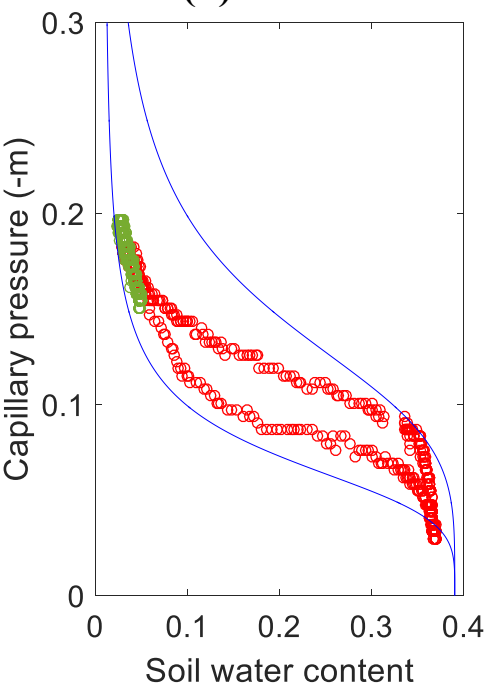

(e) $1818 \mathrm{~s}$

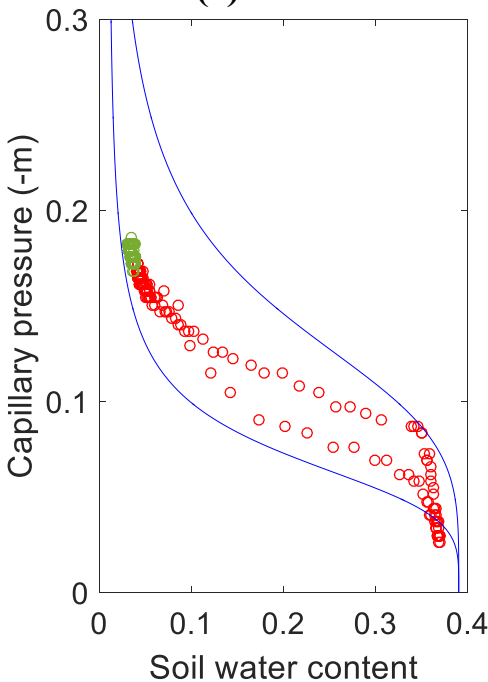

(h) $588 \mathrm{~s}$

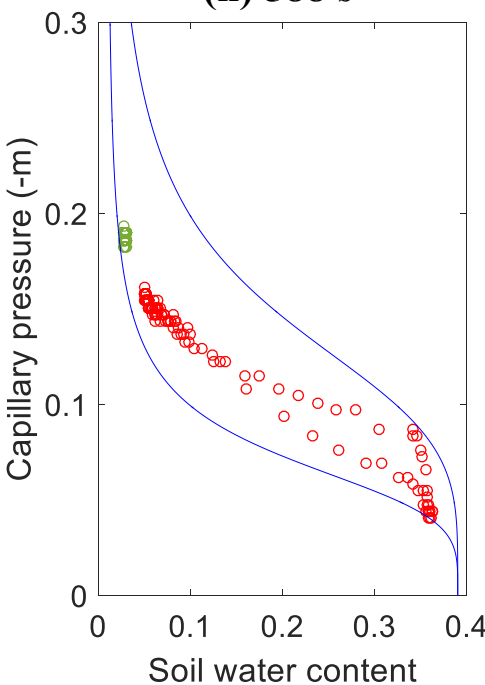

(c) $5000 \mathrm{~s}$

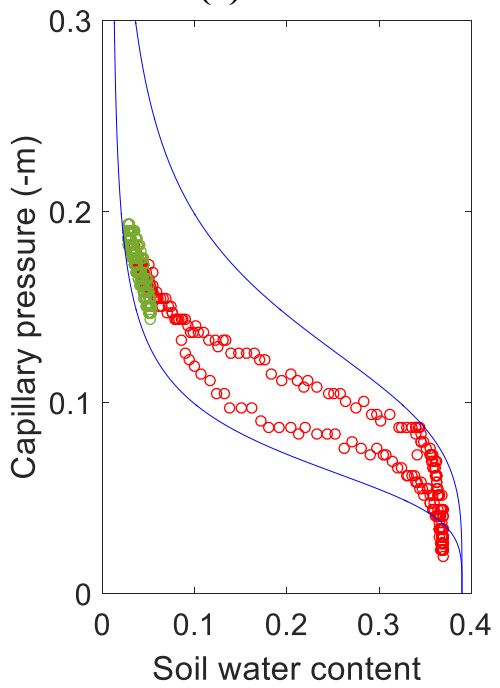

(f) $1250 \mathrm{~s}$

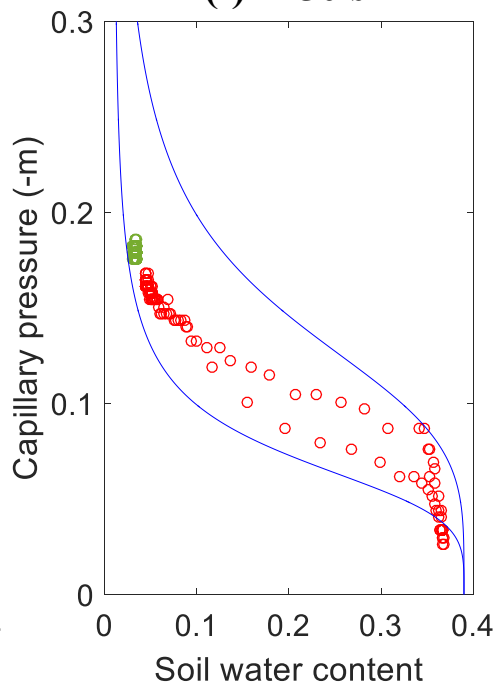

(i) $299 \mathrm{~s}$

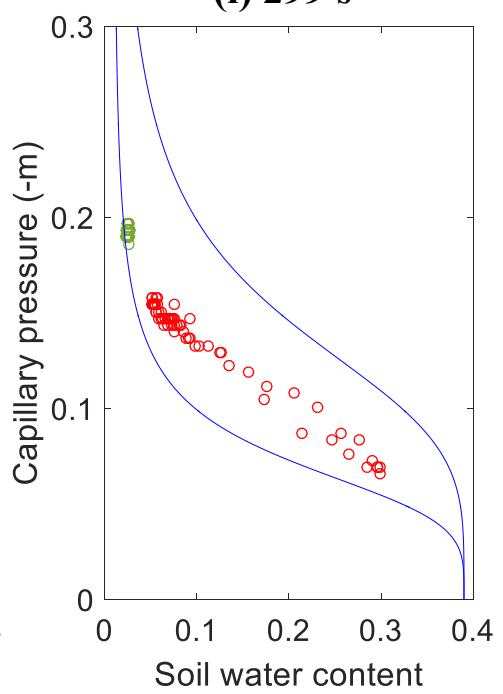

Figure 8. Measurements of the WRC at $z=0.17 \mathrm{~m}$ (red circles) and $z=0.27 \mathrm{~m}$ (green circles) for different watertable fluctuations having the same amplitude of $0.14 \mathrm{~m}$ but different periods 
as indicated. The blue lines represent the static WRC under drainage and imbibition conditions, i.e., static main drying (MD) and wetting (MW) curves. Note that the data presented in each panel were measured over a full fluctuation period. 
(a) $20000 \mathrm{~s}$

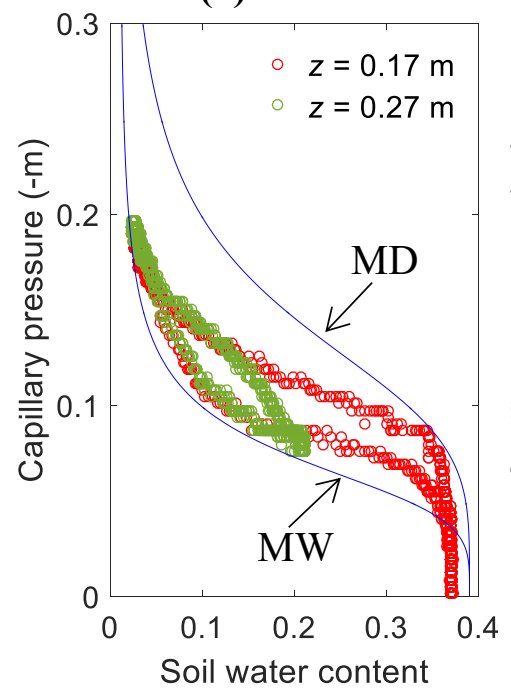

(d) $4000 \mathrm{~s}$

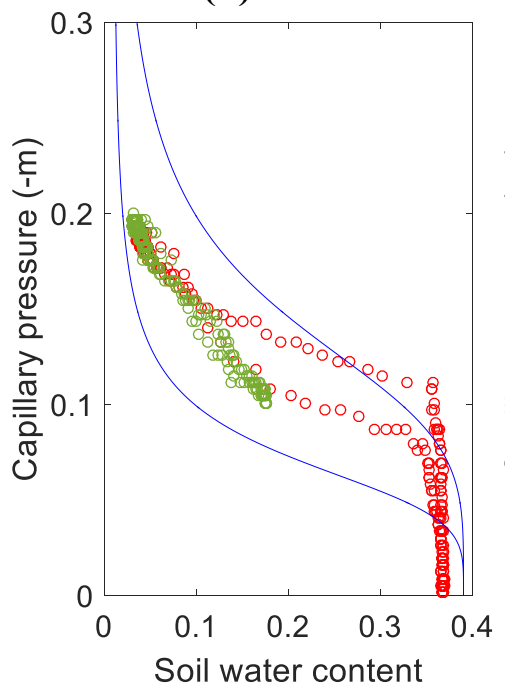

(b) $10000 \mathrm{~s}$

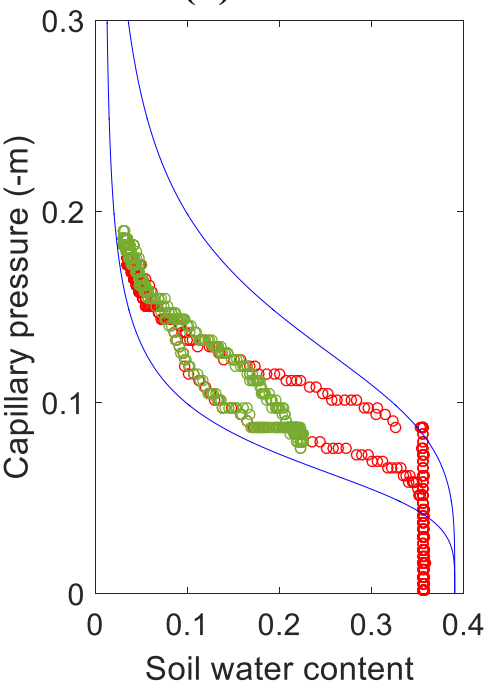

(e) $2857 \mathrm{~s}$

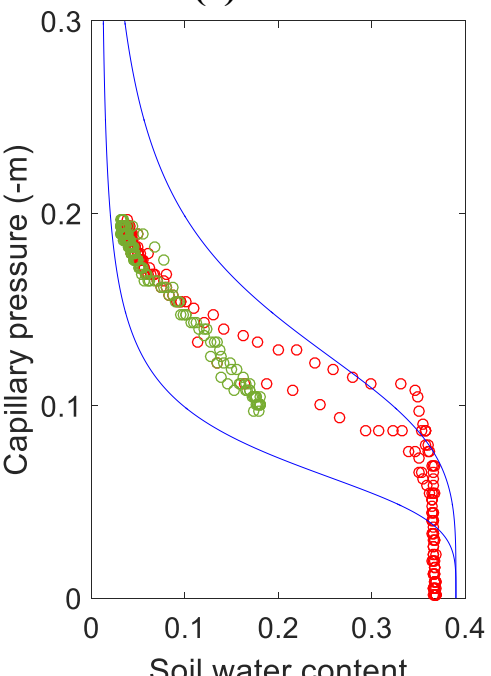

(c) $5000 \mathrm{~s}$

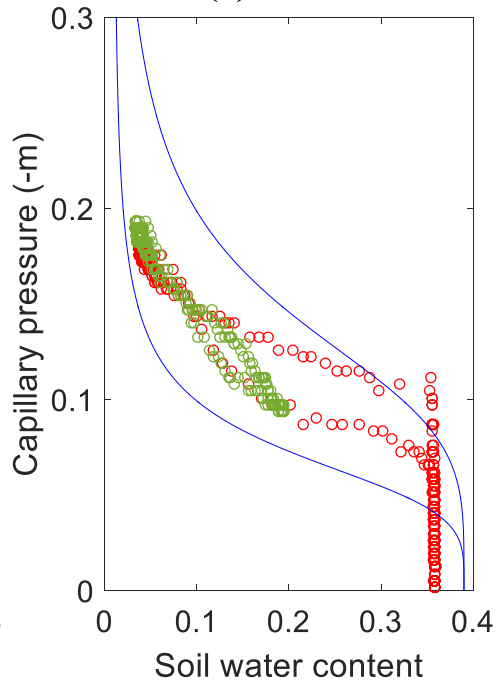

(f) $1818 \mathrm{~s}$

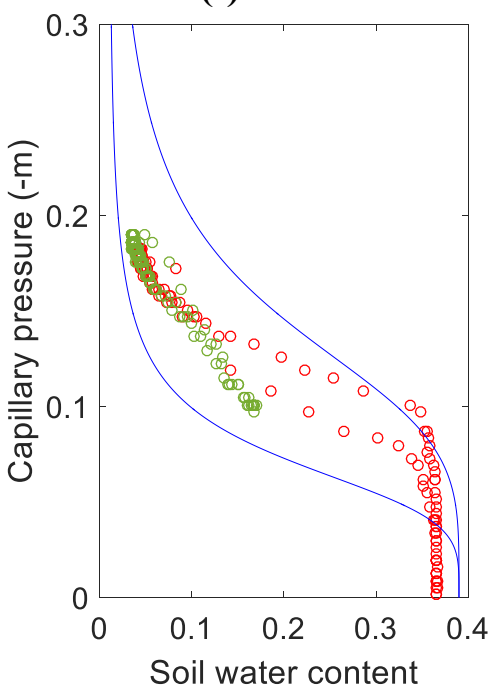

(g) $1250 \mathrm{~s}$

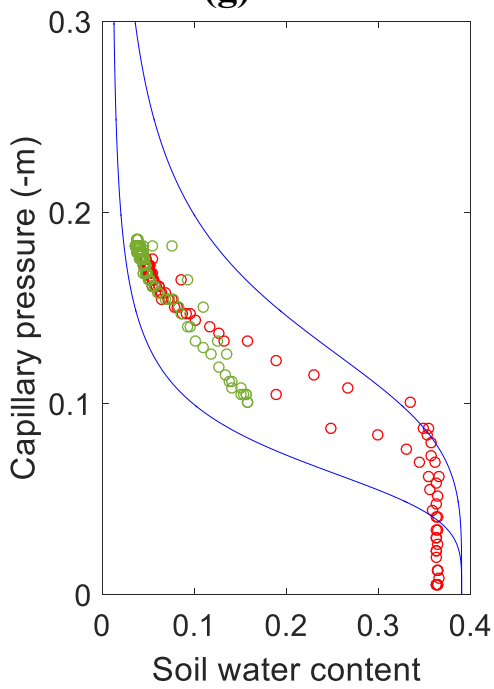

(h) $909 \mathrm{~s}$

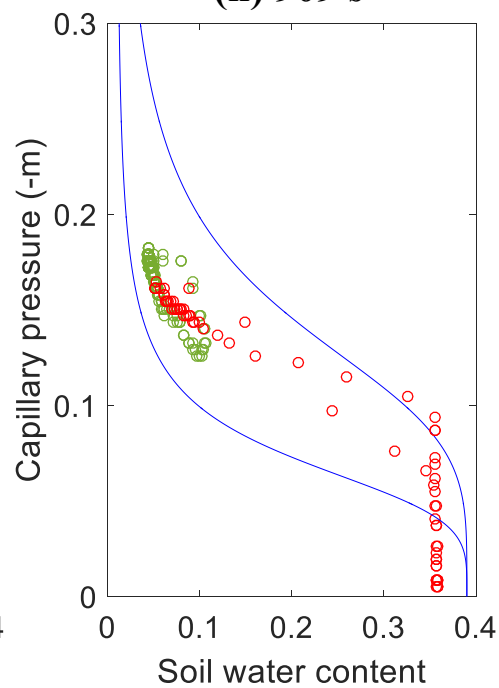

Figure 9. Measurements of the WRC at $z=0.17 \mathrm{~m}$ (red circles) and $z=0.27 \mathrm{~m}$ (green circles) for different watertable fluctuations having the same amplitude of $0.19 \mathrm{~m}$ but different periods 
as indicated. The blue lines represent the static WRCs under drainage and imbibition conditions, i.e., static main drying (MD) and wetting (MW) curves. Note that the data presented in each panel were measured over a full fluctuation period. 

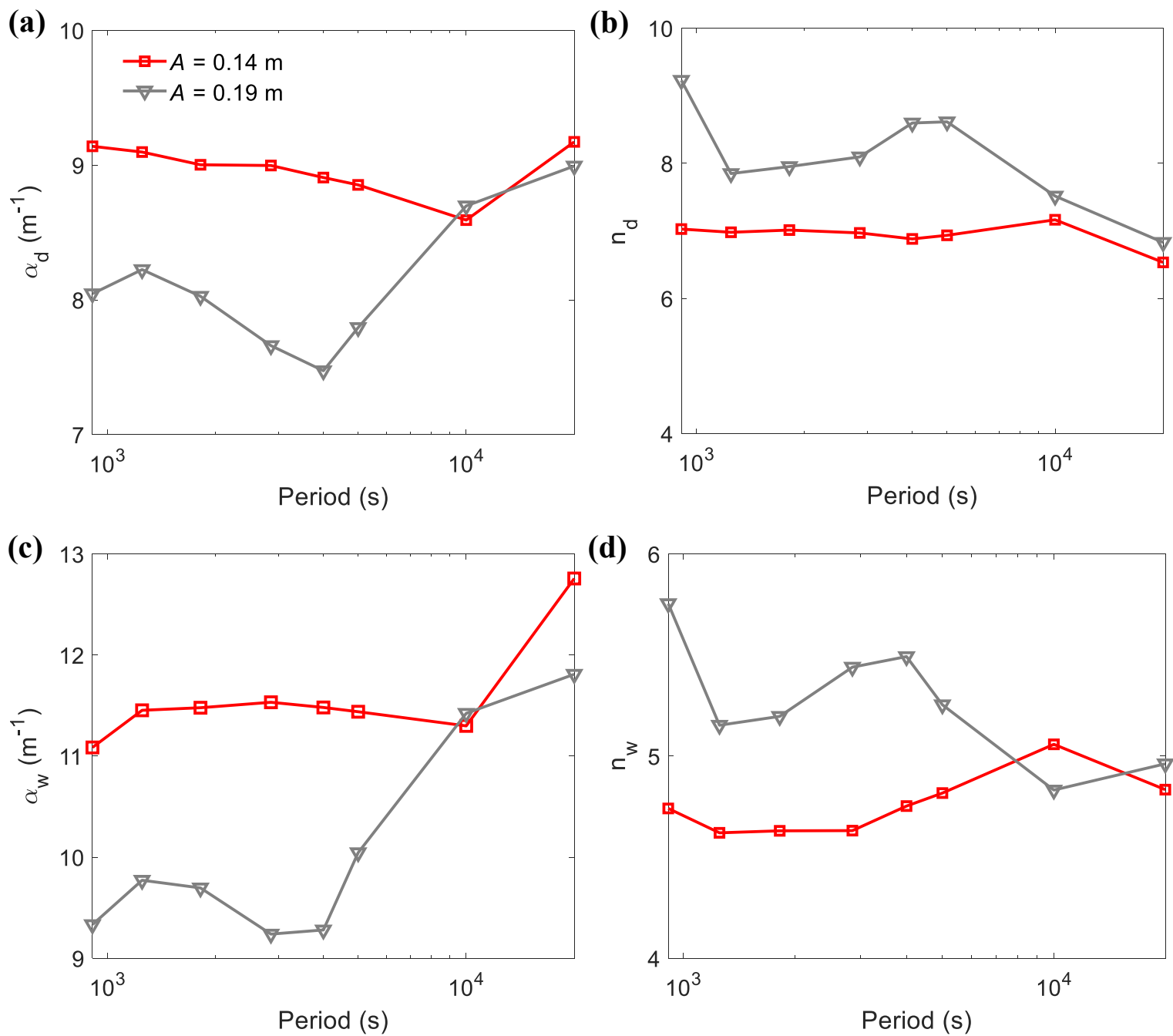

Figure 10. Values of (a) $\alpha_{d}$, (b) $n_{d}$, (c) $\alpha_{w}$, and (d) $n_{w}$ for different watertable fluctuation periods and amplitudes. 


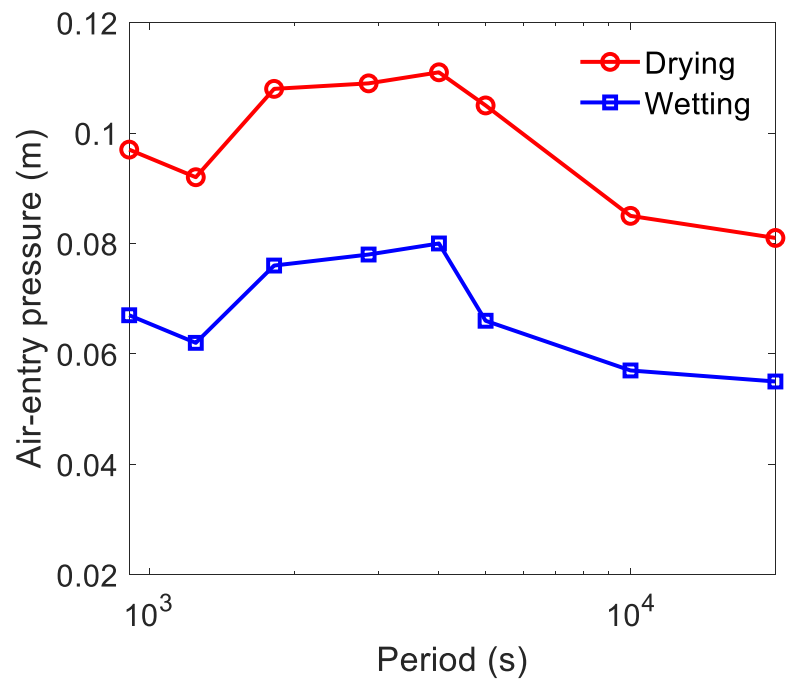

Figure 11. Values of air-entry pressure for the drying and wetting processes of watertable fluctuations with an amplitude of $0.19 \mathrm{~m}$ but different periods. 
(a) $20000 \mathrm{~s}$

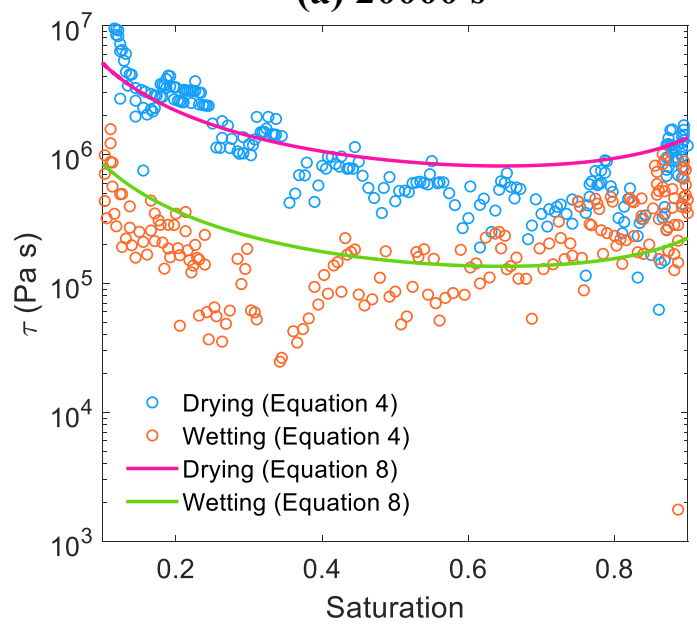

(c) $4000 \mathrm{~s}$

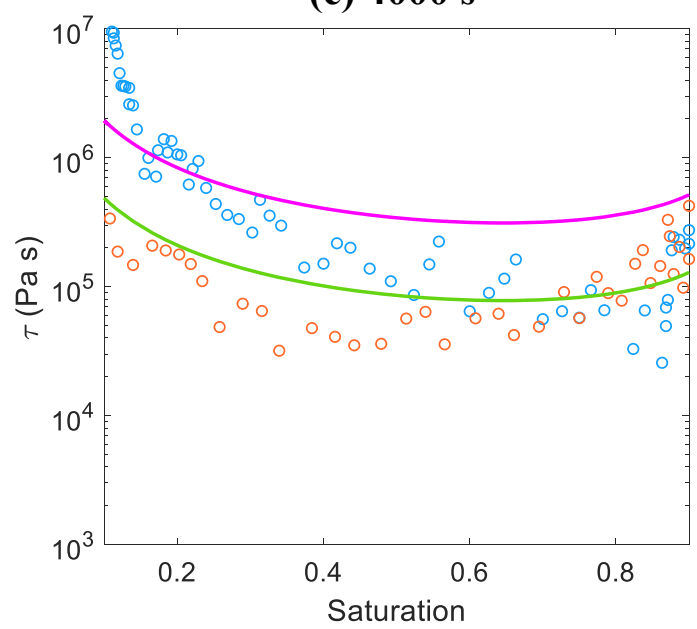

(e) $1818 \mathrm{~s}$

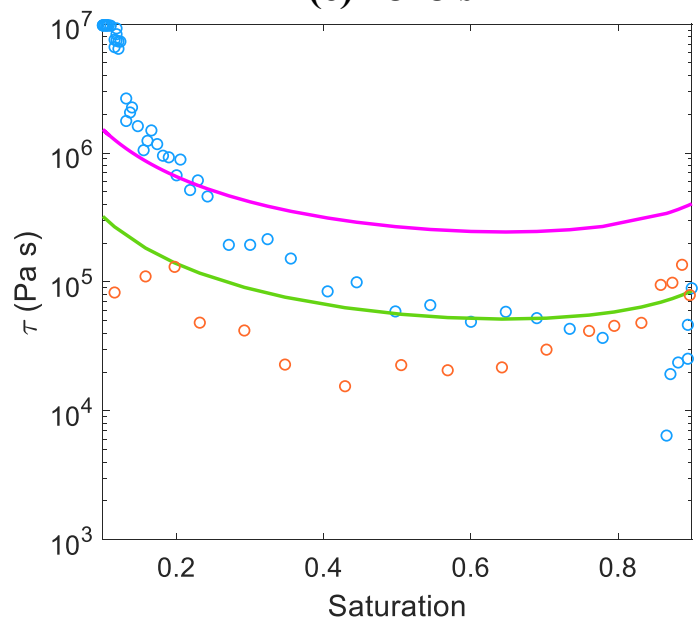

(b) $10000 \mathrm{~s}$

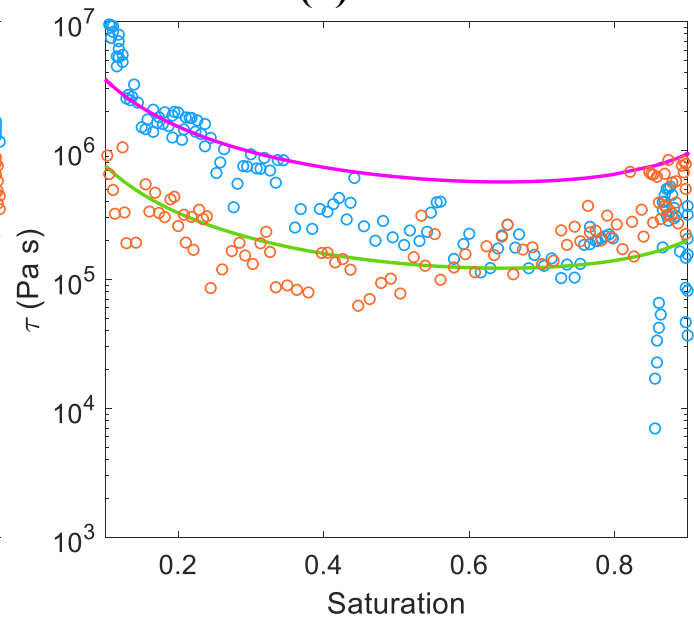

(d) $2857 \mathrm{~s}$

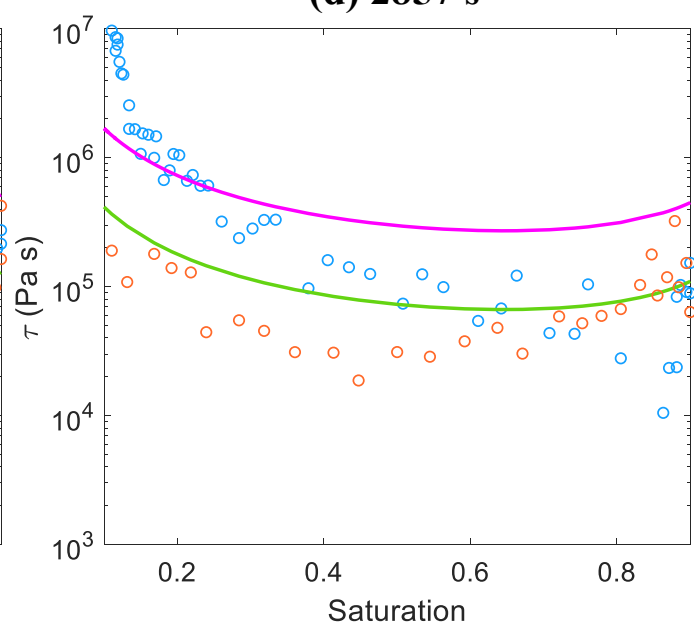

(f) $909 \mathrm{~s}$

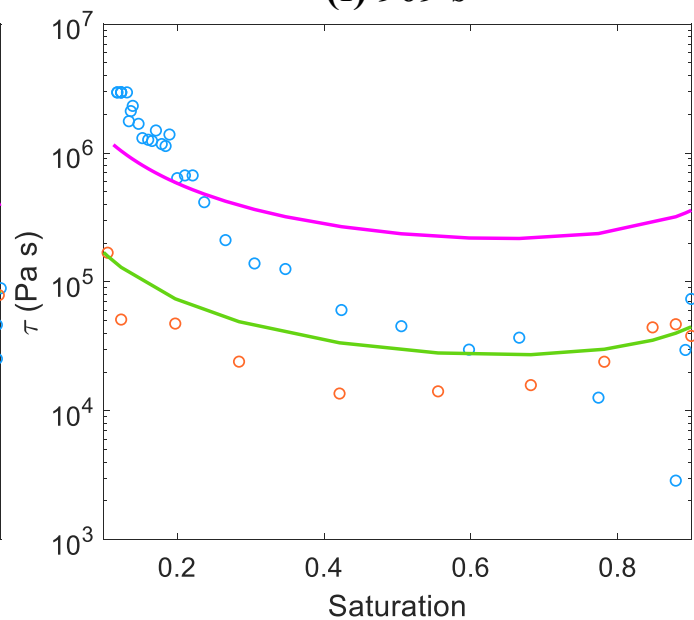

Figure 12. Calculated $\tau$ values for different watertable fluctuations with amplitude of 0.14 $\mathrm{m}$ and periods as indicated. 
(a) $20000 \mathrm{~s}$

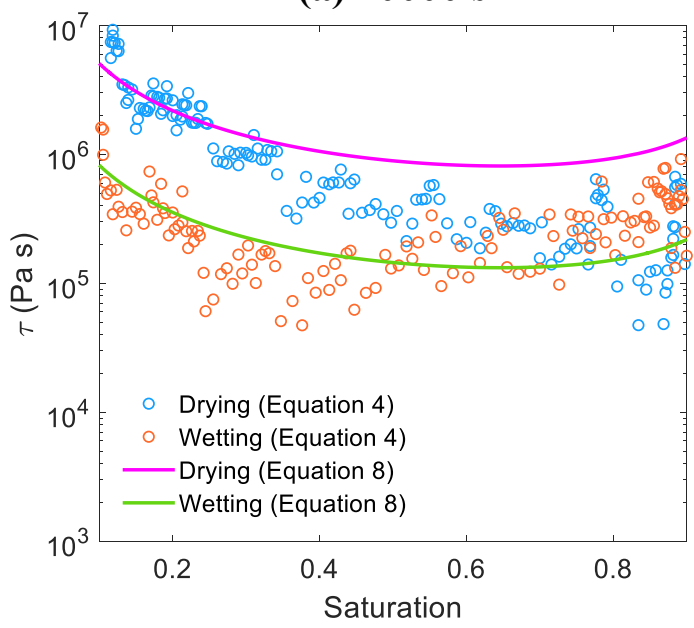

(c) $4000 \mathrm{~s}$

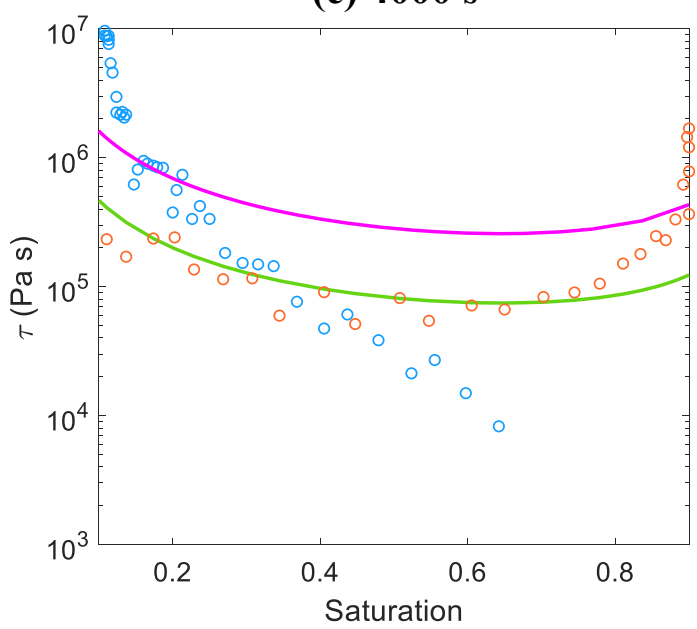

(e) $1818 \mathrm{~s}$

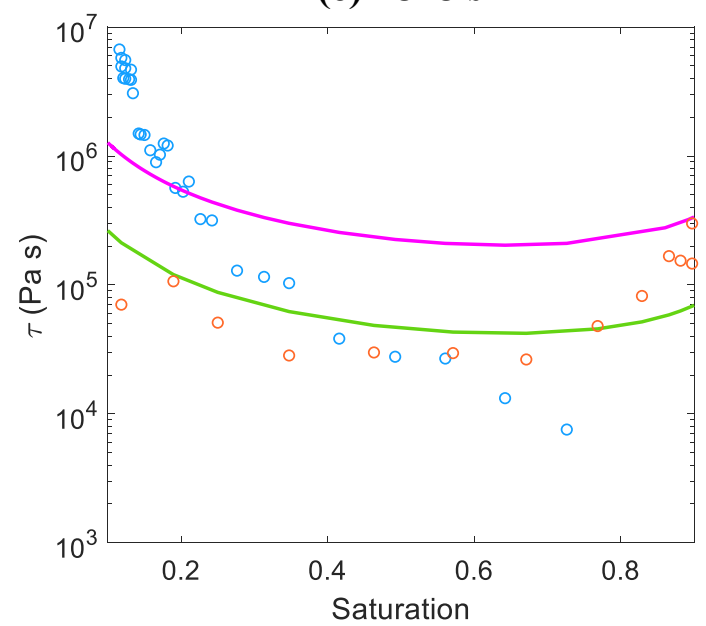

(b) $10000 \mathrm{~s}$

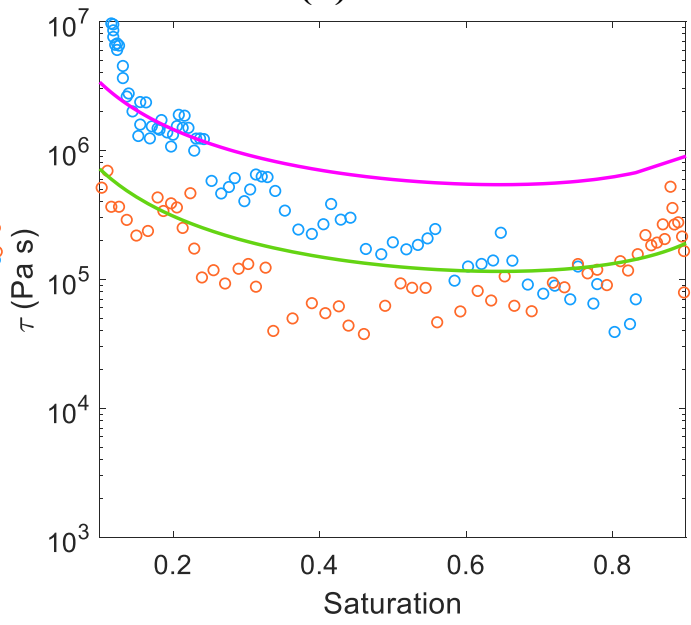

(d) $2857 \mathrm{~s}$

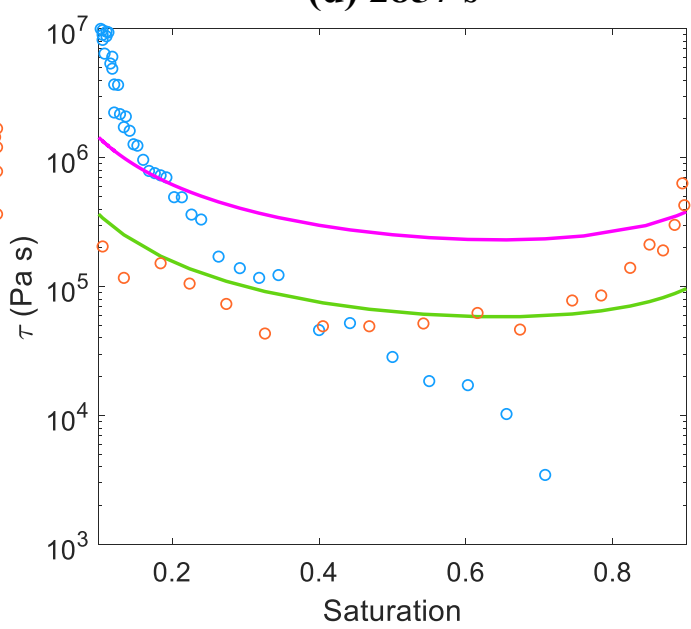

(f) $909 \mathrm{~s}$

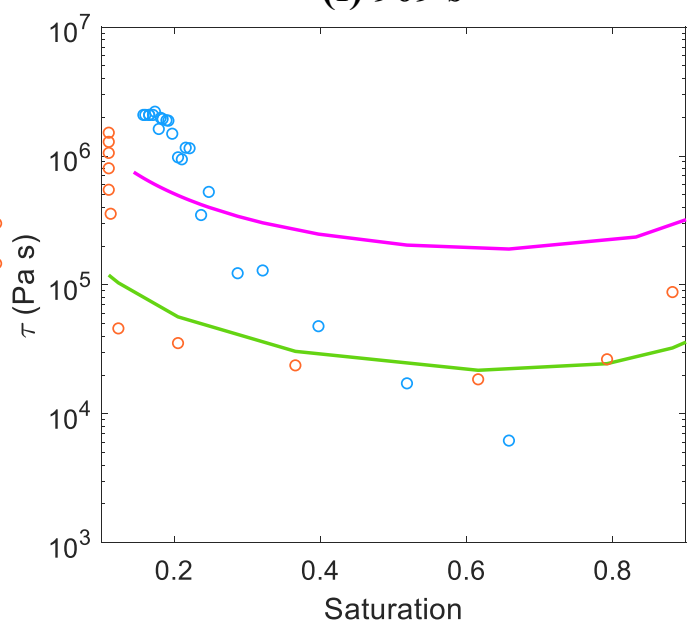

Figure 13. Calculated $\tau$ values for different watertable fluctuations with amplitude of 0.19 $\mathrm{m}$ and periods as indicated. 

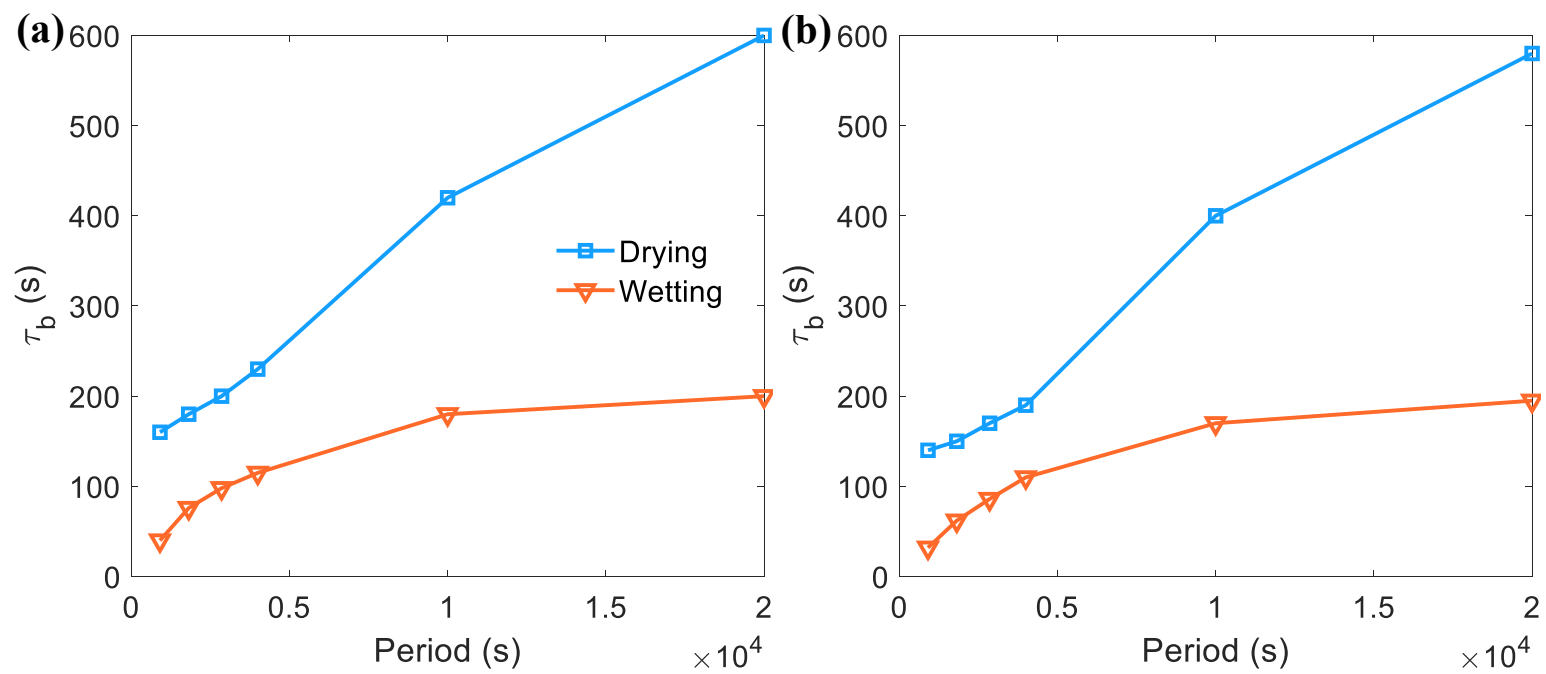

Figure 14. Calculated redistribution time $\tau_{b}$ values for watertable fluctuations with amplitudes of (a) $0.14 \mathrm{~m}$ and (b) $0.19 \mathrm{~m}$. 